Board of Governors of the Federal Reserve System

International Finance Discussion Papers

Number 713

November 2001

CONVERGENCE IN NEOCLASSICAL VINTAGE CAPITAL GROWTH MODELS

Brett D. Berger

NOTE: International Finance Discussion Papers are preliminary materials circulated to stimulate discussion and critical comment. References to International Finance Discussion Papers (other than an acknowledgment that the writer has had access to unpublished material) should be cleared with the author or authors. Recent IFDP's are available on the Web at www.federalreserve.gov/pubs/ifdp/ 


\title{
CONVERGENCE IN NEOCLASSICAL VINTAGE CAPITAL GROWTH MODELS
}

\author{
Brett D. Berger*
}

\begin{abstract}
Most growth models assume capital is homogeneous. This contradicts intuition and empirical evidence that the majority of technology is embodied in the capital stock. Classic papers from the late 1950's and 1960's show that non-optimization models display the same asymptotic growth rates whether technology is embodied (vintage capital) or disembodied. This paper uses new numerical optimization techniques to solve for the entire time paths of the key economic variables for optimization versions of the three main types of vintage capital models. The conclusion is that although steady state growth rates may be the same, the transition paths, especially as characterized by convergence rates, vary greatly between the vintage and nonvintage capital models.
\end{abstract}

Keywords: productivity, technology,

**The author is an economist in the Division of International Finance, Board of Governors of the Federal Reserve System. He can be reached at Mail Stop 42B, Federal Reserve Board, Washington, DC 20551; brett.d.berger@frb.gov. The majority of this research was done while the author was a graduate student at the University of Washington. The author is grateful for the comments from his supervisory committee, Stephen Turnovsky, Charles Engel, Richard Hartman, and Terry Rockafellar, and for comments from colleagues at the Board. The views of this paper are solely the responsibility of the author and should not be interpreted as reflecting the views of the Board of Governors of the Federal Reserve System. 


\section{Introduction}

The assumption that capital is homogeneous is a key building block of most growth models. This assumption contradicts intuition and empirical evidence that the majority of advances in technology are embodied in the capital stock. It is tempting to conclude that it makes little difference whether is is assumed that technological change is embodied in capital (vintage capital) or disembodied (homogeneous capital). After all, papers from the late 1950's and 1960's show that neoclassical models with constant savings rates display the same asymptotic growth rates whether technological change is embodied or disembodied. However, the question of whether alternative assumptions about capital embodiment have different implications for transitional dynamics was left open because the techniques to answer it were not available at the time.

In this paper I extend the analysis of capital embodiment. I update the analysis by replacing the constant savings rate with optimal savings behavior. In a more fundamental departure from earlier studies, I use new numerical optimization techniques to solve for the entire optimal time paths of the key economic variables. I confirm the result that steady state growth rates are the same regardless of the capital embodiment assumptions. Breaking new ground, I find that the transitional dynamics vary greatly between the vintage and non-vintage capital versions of the models.

I examine the transitional dynamics of the models by focussing on two convergence hypotheses, $\beta$-convergence and $\sigma$-convergence. The $\beta$-convergence 
hypothesis is the hypothesis that "poor economies grow faster than rich economies." The $\sigma$-convergence hypothesis is the hypothesis that the levels of per capita output of different economies will converge. It can only be examined by numerical methods because the time path of the level of output is required. The results of this paper concerning $\sigma$-convergence are therefore new for both the vintage and non-vintage versions of the models. My results show for the first time that conditional $\sigma$-convergence occurs for both the non-vintage and vintage capital versions of the models, and that the rates of both $\beta$-convergence and $\sigma$-convergence are higher in the vintage capital versions.

The models examined in this paper are discrete time, finite horizon, parameterized, optimization versions of the three main types of neoclassical vintage capital models (the types are described in section 4). The algorithms used to obtain the solutions to these models fall under the category of path-following algorithms. This is a relatively new class of algorithms not previously utilized in examining macroeconomic models. ${ }^{2}$ This class of algorithms has been shown to be highly effective in large-scale optimization problems (Wright 1997). This effectiveness is reflected in the present work. Each of these models contain two to six thousand variables, yet running on a personal computer, the algorithms terminate within a few hours (usually within an hour). A brief

\footnotetext{
${ }^{1}$ The definitions of $\sigma$-convergence and $\beta$-convergence are defined as in Sala-i-Martin (1996). The terms were first introduced in Sala-i-Martin (1990).

${ }^{2}$ Only 1 citation on Econlit was found (as of September 2001) applying a similar algorithm to a model. R. Ostermark, "Solving a Linear Multiperiod Portfolio Problem by Interior-Point Methodology," Computer-Science-in-Economics-and-Management 5(4), November 1992, pp. 283-302.
} 
description of the algorithms is contained in section 5. A more detailed description can be found in Berger (2001).

The paper is divided into the following sections. Section 2 discusses the relevant background convergence literature. Section 3 explains in greater detail the differences in the types of technology and the technical difficulties of examining vintage capital models. Section 4 contains general descriptions of the three models as well as explanations of the common parameters used. Section 5 is a brief description of the optimization method. Sections 6, 7, and 8 each give a detailed explanation of one of the models and the corresponding results. Section 9 is a conclusion, and an appendix that mathematically describes $\beta$-convergence and $\sigma$-convergence follows.

\section{Convergence}

While the $\sigma$-convergence hypothesis has been examined in the empirical literature, this is the first examination of $\sigma$-convergence in a theoretical paper. Previously, it was possible to derive only steady-state growth rates and the transitional dynamics (linearized) around the steady state. This approach does not provide enough information to examine the levels of output or consumption. Therefore the literature is often limited to asking whether "poor economies grow faster than rich economies," that is, whether there is $\beta$-convergence.

However, if per capita output is used as the measure of "rich" and "poor", the $\beta$ convergence hypothesis is only relevant to different economies at the same point in time and cannot be applied to the same economy at different points in time. For example, all 
economies examined in this paper are getting richer in the usual sense that per capita output is always increasing. If a particular economy approaches the steady-state growth rate from below, as time passes, the economy becomes much richer in terms of per capita output but the economy is also growing faster. In order for $\beta$-convergence to hold for a single economy as time passes, "poor" and "rich" must be defined relative to a steady state constant.

Galor (1996) suggests a useful refinement of the $\sigma$-convergence hypothesis into three different forms, which can also be applied to the $\beta$-convergence hypothesis. Galor's convergence hypotheses are the absolute convergence hypothesis, the conditional convergence hypothesis, and the club convergence hypothesis. The absolute convergence hypothesis predicts that, in the long run, regardless of economies' initial conditions and their structural characteristics (e.g., population growth rate, preferences, government intervention, 1 etc.), per capita output of economies will converge. Conditional convergence requires that structural characteristics of economies be identical if convergence is to occur. Identical structural characteristics as well as sufficiently proximate initial conditions are necessary under the $c l u b$ convergence hypothesis. This last hypothesis assumes multiple stable equilibria.

Economists have empirically rejected the absolute form of $\beta$-convergence. Barro (1991) states that "per capita growth rates have little correlation with the starting level of per capita product." ${ }^{33}$ On the other hand, the conditional form of $\beta$-convergence is supported by Barro (1991), Mankiw, Romer, and Weil (1992), and Barro and Sala-i- 
Martin (1992). Mankiw et. al find that when controlling for variances in structural variables such as investment and population growth rates, there is a "strong tendency for poor countries to grow faster than rich ones."4 Quah (1996) provides empirical evidence of club $\beta$-convergence.

The rate of $\beta$-convergence is a subject of intense debate. Articles such as Sala-iMartin (1996), and Barro and Sala-i-Martin (1992) show a convergence rate of approximately $2 \%$ in their cross country regressions, and this is usually taken as the benchmark rate. Evans (1997) shows a higher rate of convergence of $7 \%$ in crosscountry regressions and up to $15 \%$ for the contiguous states of the United States.

Barro and Sala-i-Martin (1995) contribute to the theoretical convergence literature by demonstrating conditional $\beta$-convergence in a Ramsey type model. They show that that if output per effective worker, $\hat{y}$, starts below its steady state level, then the growth rate of output per worker will decline monotonically toward its steady state growth rate. Their model is a continuous time, infinite horizon model with exogenous labor augmenting technological growth and Cobb-Douglas production. As shown in Appendix $1, \beta$-convergence is a necessary, but not sufficient condition, for monotonic $\sigma$ convergence.

\footnotetext{
${ }^{3}$ Barro 1991, pp. 407-408.

${ }^{4}$ Mankiw et al. 1992, p.428.
} 


\section{Vintage Capital}

Technological progress is widely accepted as the primary engine of sustained growth in per capita output. There are two basic ways of modeling technology, as embodied or disembodied. Embodied technology is inherent in the capital stock of the economy. Therefore, to access new technology, the economy must invest in new capital. Embodied technology models are often referred to as "vintage capital" models because the capital stock is heterogeneous, with each vintage characterized by the technology available at the time of its construction.

Disembodied technology, however, affects all capital (or the entire productive process). It is not necessary to invest in order to capture advances in disembodied technology. The prototypical example of an advance in disembodied technology is the introduction of the assembly line. This innovation did not create a new factor of production but instead reorganized existing factors in a manner that improved productivity.

The first growth models featured disembodied technology, but in the late 1950's and 1960's, embodied technology models were developed in an attempt to more accurately capture the way technology enters the economy. Unfortunately, these vintage capital models have inherent in them the difficulty of tracking multiple capital stocks. In a continuous time model, there would be an infinite number of capital stocks even over a finite time horizon. A discrete time, infinite horizon model would also have an infinite quantity of stocks. Because of the difficulty of vintage capital models, the literature only examined asymptotic steady state results, derived by using aggregate capital stocks or 
assuming that the depth of capital, the number of vintages used each period, is constant. This paper solves the problem of tracking multiple capital stocks and the accompanying large-scale nature of the models to obtain numerical solutions to optimization versions of the classic vintage capital models. The numerical solutions to the models are the entire time paths of consumption, output, capital, and their associated shadow values.

\section{General Model Descriptions}

The three models examined are referred to as "putty-putty," "clay-clay," and "putty-clay." They differ in the assumptions regarding the substitutability of factors of production. "Putty" implies that labor and capital can be paired in any ratio, while "clay" refers to a fixed capital-labor ratio. The first word in each pair describes conditions at the time of installation of the capital and the second word refers to all time after the installation. For example, the term putty-clay refers to a model in which the capital-labor ratio may be chosen at the time of capital installation, but for all time thereafter, labor must be used with that vintage of capital according to the chosen proportion.

Each of the three models is based on the basic consumption-savings model. A central planner of the economy chooses a time path of consumption with the objective of maximizing the population's sum of discounted utility, which is solely a function of consumption. Utility is represented by a constant-elasticity-of-intertemporal-substitution utility function:

$$
\begin{aligned}
u\left(C_{t}\right) & =\frac{1}{1-\gamma}\left(C_{t}^{1-\gamma}-1\right) & & \gamma \neq 1 \\
& =\ln \left(C_{t}\right) & & \gamma=1
\end{aligned}
$$


The elasticity of intertemporal substitution equals $-\frac{1}{\gamma}$, and for fixed $C_{t},(1)$ is a continuous function of $\gamma$.

The three models are based on a Cobb-Douglas production function. The function has the form:

$$
f_{v}\left(N_{v}, K_{v}\right)=d_{t} A_{v} N_{v}^{1-\alpha} K_{v}^{\alpha}
$$

where $v$ represents the vintage, $A_{v}$ is the embodied technology parameter, and $0<\alpha<1$. Total output for period $t$ is:

$$
f_{t}=d_{t} \sum_{v=1}^{V+t-1} A_{v} N_{v}^{1-\alpha} K_{v}^{\alpha}
$$

where $V$ is the number of vintages available in the initial period (a new vintage becomes available each period), and $d_{t}$ is the disembodied technology parameter. $d_{t}$ and $A_{v}$ could be combined into a single parameter, $A_{t, v}$, incorporating both the disembodied and embodied technological growth.

An important difference between vintage and non-vintage models is that the allocation of labor becomes a non-trivial problem in the vintage case. In growth models, the main utility maximization encapsulates another maximization problem. Each period the planner or representative agent must maximize production given the factors of production available that period. When capital and labor are homogeneous and production Cobb-Douglas, the solution is simply to use all of the available capital and labor together. Therefore the production function usually seen in growth models is the indirect production function resulting from a one period maximization. For vintage 
capital models, labor must be allocated to each vintage. Only in the putty-putty case does this allocation have a unique closed form solution that leads to a new indirect production function utilizing an aggregate capital stock (see section 4 and Berger (2001)). There is no such closed form solution for the clay-clay and putty-clay models.

Several parameter values are common to all three models, and are approximately the same as those used in previous numerical papers. For all three models, $\alpha$, the production elasticity of capital, is set equal to 0.35 , the historic share of income paid to capital when capital is defined in the traditional narrow sense (i.e. not including human capital, Maddison (1987)). $\beta$, the discount factor reflecting the planner's rate of time preference, is set equal to 0.97 . The population growth rate, $n$, is equal to $1.5 \%$, which reflects that the models are calibrated more closely to industrialized countries. The number of vintages available in the initial period, $V$, equals 2 for all of the models. This value was chosen so that the clay-clay model would not be labor constrained initially, and was kept the same in the other models for consistency. Although vintages aren't explicitly tracked in the putty-putty model with an aggregate capital stock, the value of $V$ does affect the initial value of the aggregate capital stock. The values of $\gamma$ used are $\gamma=1,2,3$, and 5 . The growth rate of technology used in the model is $3 \%$, whether embodied or disembodied. This value was chosen because of its use in the literature and because it is empirically supportable. Greenwood et al. (1997) find annual growth in investment-specific productivity (embodied growth) to be $3.2 \%$. 


\section{Optimization Method}

Two different path-following algorithms are used to obtain the results in this paper. An interior-point algorithm is used for the putty-putty and clay-clay models. An interior-point algorithm is so named because at each iteration all of the variables are in the interior of the feasible set. This is achieved through the use of penalty functions which go to infinity as the boundary of the feasible set is approached. In effect, the original optimization problem is replaced by an unconstrained problem in which penalties based upon constraint values are imposed. The penalty functions are multiplied by a positive scalar, $\mu$, which decreases monotonically with the iterations. Each value of $\mu$ represents a different unconstrained problem to which a solution can be found. The sequence of solutions to the unconstrained problems are the points comprising the "central path." It is this path of solutions which is followed to the solution of the original problem. As $\mu \rightarrow 0$, the solutions to the unconstrained problems go to the solution of the original problem.

A non-interior path-following algorithm is used to obtain results for the putty-clay model. The algorithm is based on Burke and $\mathrm{Xu}$ (2000), though their setup is for a linear model as opposed to a general nonlinear model such as the putty-clay model of this paper. Instead of penalty functions, a new function $\phi(x, v, \mu)$ is introduced where $x$ is a vector of the primal variables and multipliers, $v$ is a vector of the value of optimality conditions, and $\mu$ is once again a positive scalar. For a given $\mu, \phi=0$ represents the solution to a relaxed version of the original problem. It can be shown that if $\mu=0$ then the optimality conditions of the original problem will be satisfied if and only if $\phi=0$. 
The path followed to the solution of the original problem is comprised of the solutions to the relaxed problems as $\mu$ is monotonically reduced at each iteration.

\section{Putty-Putty Model}

The putty-putty vintage capital model was introduced in Solow (1959). In that paper Solow showed that a continuous-time version of equation (3) could be rewritten using an aggregate capital term. In Berger (2001), it is shown that this holds for the discrete time function. The rewritten function is:

$$
f_{t}\left(N_{t}, Q_{t}\right)=d_{t} N_{t}^{1-\alpha} Q_{t}^{\alpha}
$$

where $Q_{t}$ is the level of the aggregate capital stock at time $t$, and

$$
Q_{t}=\sum_{v=1}^{V+t-1} A_{v}^{1 / \alpha} K_{v}
$$

$V+t-1$ is the number of vintages available at time $t$ given $V$ vintages available in time period 1. Hence, $Q_{t}$ is a weighted sum of the stock of each available vintage with the weights a function of the technology embodied by each vintage. (5) leads to the dynamic equation in $\left(P_{p p}\right)$, the model formulation which follows. The putty-putty model used here is a discrete time version of the Phelps (1962) model with a finite time horizon. Phelps (1962) extended the work of Solow (1959) by explicitly deriving the dynamic capital equation and steady state growth rate. The Phelps and Solow models, unlike this paper, use a constant rate of savings and are divorced from dynamic optimization. In all

of the models, technological growth is exogenous. The model $\left(P_{p p}\right)$ below allows for 
both embodied and disembodied technology. When technology is embodied there is heterogeneity in the capital stock; and when technology is entirely disembodied the model reduces to the standard Ramsey, Cobb-Douglas, growth model. Because there are no stochastic elements in the model, the central planner is choosing the entire time path of consumption in the initial period. The formal optimization problem is:

$$
\begin{aligned}
& \text { Maximize } \sum_{t=1}^{T} \beta^{t-1} \frac{1}{1-\gamma}\left(C_{t}^{1-\gamma}-1\right) \\
& \text { over } \quad C_{t}, Y_{t}, Q_{t} \quad \text { for } t=1 \ldots T \\
& \text { subject to: } \\
& \quad C_{t} \geq 0 \\
& \quad Y_{t}=d_{t} N_{t}^{1-\alpha} Q_{t}^{\alpha} \\
& \quad Y_{t}-C_{t} \geq 0 \\
& \quad Q_{1}=\bar{Q} \\
& \quad Q_{t+1}=Q_{t}+A_{V+t}^{1 / \alpha}\left(Y_{t}-C_{t}\right) \quad \text { for } t=1 \ldots T-1 .
\end{aligned}
$$

$C_{t}$ is the chosen level of consumption in period $t . Y_{t}$ is the chosen level of output in period $t . Q_{t}$ is the level of the aggregate capital stock at time $t . N_{t}$ is the given labor stock each period. $\bar{Q}$ is the given level of aggregate capital stock in the initial period, where $\bar{Q}=\sum_{v=1}^{v} A_{v}^{1 / \alpha} \bar{K}_{v} . \bar{K}_{v}$ is the given initial level of capital of vintage $v . d_{t}$ is the given level of disembodied technology at time $t . A_{V+t}$ is the given level of embodied technology corresponding to the vintage produced at time $t$. The technology parameters grow at a constant rate, such that $A_{V+t}=\bar{A}\left(1+g_{e}\right)^{t}, d_{t}=\bar{d}\left(1+g_{d}\right)^{t-1}$, and $N_{t}=\bar{N}(1+n)^{t-1}$, where $\bar{A}, \bar{d}, \bar{N}, n, g_{d}$ and $g_{e}$ are exogenous parameters. $T$ is the given 
total number of time periods. It is shown in Berger (2001) that this problem can be written as a convex programming problem and therefore has a unique global solution.

Parameter values unique to the putty-putty model are:

$$
T=200 \quad \bar{N}=\bar{A}=\bar{d}=\bar{K}_{v}=1 .
$$

The above parameters give $\bar{Q}=1.9709$ when technology is entirely embodied, and $\bar{Q}=2$ when technology is entirely disembodied. The cases with simultaneous embodied and disembodied technological growth are not examined in this paper.

The optimal time paths of output and consumption have the same steady-state growth rates across all the differing parameter values of $\gamma$ and types of technological change (Figures 1 and 2). This is not surprising since output and consumption series created by assuming a constant savings rate have identical steady-state growth rates that are insensitive to the choice of the savings rate. Phelps (1962) found the asymptotic growth rate to be $g_{Y}=\frac{g_{e}+g_{d}}{1-\alpha}+n$. This is approximately the asymptotic rate found here. The difference is attributable to the difference between the discrete time of this model and the continuous time of the Phelps model. The asymptotic growth rate of output and consumption in the discrete-time model is:

$$
g_{Y}=\left(\left(1+g_{e}\right)\left(1+g_{d}\right)\right)^{\frac{1}{1-\alpha}}(1+n)-1
$$

Thus, in switching from continuous to discrete time it is no longer true that only the total amount of technological growth (disembodied and embodied) affects the growth rate, although the difference from splitting the source of technology is small. From the dynamic equation it can be seen that aggregate capital grows at the rate: 


$$
g_{Q}=\left(1+g_{Y}\right)\left(1+g_{e}\right)^{1 / \alpha}-1
$$

At the given parameter values, $g_{Q}=15.58 \%$ when technology is embodied, and $g_{Q}=g_{Y}=6.22228 \%$ when technology is disembodied.

These discrete time models demonstrate turnpike behavior (Blanchard and Fischer (1989)). The calibrated models converge toward the discrete time asymptotic steady state growth rate of output, $g_{Y}=6.22228 \%$, but they then turn away as the terminal point of the model approaches (Figures 1 and 2). There is no salvage value of capital so consumption equals output in the final period. The behavior differs somewhat from the typical turnpike behavior for the values of $\gamma$ that approach the steady state from above. Since the value of investment goes to zero as the terminal period approaches, less is invested in the final periods and the growth rate decreases. Therefore, for these $\gamma$-values, the growth rate actually passes through the asymptotic steady state level (Figures 1 and 2).

For examining a single economy at different points in time, a steady-state constant must be used to determine whether the economy is rich or poor. The constant used is the output-effective labor ratio:

$$
\hat{Y}_{t}=\frac{Y_{t}}{\theta_{t} N_{t}}
$$

where $Y_{t}$ is total output, $N_{t}$ is the labor supply, and $\theta_{t}=\left(A_{V+t-1} d_{t}\right)^{\frac{1}{1-\alpha}}$ is the level of 
technology adjusted such that it has the same production elasticity as labor (when technology is disembodied). ${ }^{5}$

Both vintage and non-vintage models can approach the steady state growth rate from above or below depending on whether the initial level of the output-effective labor ratio is above or below the steady state level (Figure 3). The steady-state level is inversely related to the value of $\gamma$ (Figure 4). In economic terms, as $\gamma$ increases the marginal utility of early consumption is relatively greater and decreases rapidly. This causes lower initial savings, a lower growth rate of output in the transition, and consequently a lower steady-state output-effective labor ratio.

The rate of $\beta$-convergence, as measured by the fraction of the distance an economy moves toward the steady state growth rate each period, is affected by whether the economy is modeled as having embodied or disembodied technology. When technology is embodied, the $\beta$-convergence rate is universally higher than in the disembodied case (Figures 5 and 6). Furthermore, the preference parameters affect the convergence rate in the embodied case, but not in the disembodied case. The steady-state convergence rate for disembodied technology is $8.7 \%$ (Figure 5), while the convergence rates of the embodied technology case range from 10.8\%-15.8\% (Figure 6). Allowing preferences to vary across regions would provide an explanation for different observed growth and convergence rates in the empirical literature. All of these rates are consistent

${ }^{5}$ The production function in $\left(P_{p p}\right)$ can be rewritten as $Y_{t}=\left(N_{t} d_{t}^{\frac{1}{1-\alpha}}\right)^{1-\alpha} Q_{t}^{\alpha}$ 
with the rates found by Evans (1997), but exceed the benchmark of 2\% commonly found in the literature.

The putty-putty model with both vintage and non-vintage capital demonstrate conditional $\sigma$-convergence in that per capita output goes to the same time path given structural characteristics, regardless of the initial level of capital (Figure 7). The figure shows the convergence of per capita output for $\gamma=1$ and 3 , and $\bar{K}=0.5$ (poor) and 4 (rich). ${ }^{6}$ It can be seen that convergence takes longer in the disembodied case. This is borne out in an examination of the $\sigma$-convergence rates (Figures 8 and 9). This rate is the fraction of the distance between the per capita outputs that is eliminated each period. The convergence rates for the non-vintage cases are $4.4 \%$ for both values of $\gamma$. The vintage capital model, however, has different rates corresponding to the values of $\gamma$. For $\gamma=1$ the convergence rate is $11.87 \%$, and it is $8.15 \%$ for $\gamma=3$.

The result that per capita output converges for both the non-vintage and vintage models is somewhat surprising. It is surprising because if series are created by imposing an exogenous, constant, savings rate on the putty-putty model, the vintage capital model demonstrates $\sigma$-convergence, but the non-vintage model does not. In the non-vintage model the difference in per capita output may initially decline but the difference eventually expands. Under most reasonable parameter values, per capita output diverges

\footnotetext{
${ }^{6}$ The figures show the corresponding levels of $Q_{1}$ that the values of $\bar{K}$ represent in the non-vintage and vintages cases
} 
immediately. ${ }^{7}$ Figure 10 shows this for a savings rate of $10 \%$, and the parameters used in the optimization model. ${ }^{8}$ The steady state convergence rate is $-0.67 \%$ (negative value indicates divergence) (Figure 11). However, the disembodied technology series shows $\beta$ convergence in that at each point in time the rich country grows more slowly than the poor country (Figure 12). The poor country approaches the steady state growth rate from above, while the rich country approaches from below. This series makes clear that although intuitively $\beta$-convergence should be associated with $\sigma$-convergence, it is quite easy to develop counter-examples. Appendix 1 details why Sala-i-Martin may be overstating the case when he says, "the existence of $\beta$-convergence will tend to generate б-convergence." 9

\section{Clay-Clay Model}

The clay-clay model, also known as the Leontief or fixed factor production model, is a discrete time variation of Solow et. al. (1966) with a finite time horizon. In addition, Solow et. al. used a constant savings rate while this model is a central planner optimization problem. The central planner maximizes societal discounted utility over a finite lifetime $T$. There is no salvage value of capital, and no aggregate capital stock. The capital stock cannot be aggregated because there is no closed form solution for the indirect production function. Thus, each vintage must be tracked separately. The capital

\footnotetext{
${ }^{7}$ This phenomenon was observed for a wide range of parameter values. Only when the technology growth rate was sufficiently low (1.7\%) did the disembodied case converge. ${ }^{8}$ The optimal savings rates for the models ranged from $5.52 \%-22.9 \%$ for the disembodied model, and $10.55 \%-28.47 \%$ for the vintage model.
} 
stock each period is a vector of $V+t-1$ elements, where $V$ is the number of vintages available in the initial period. The savings of period $t$ becomes the amount of capital of vintage $V+t$.

In the most intuitive form of the model $\left(P_{c c}{ }^{\prime}\right), C_{t}$ is the chosen level of consumption in period $t . Y_{t v}$ is the chosen level of output in period $t$ using capital of vintage $v . K_{t v}$ is the amount of capital available at time $t$ of vintage $v . N_{t v}$ is the amount of labor at time $t$ applied to vintage $v . N_{t}$ is the given labor stock each period. $a_{t v}$ is the given level of productivity of labor in time period $t$ of vintage $v . d_{t v}$ is the given level of productivity of capital in time period $t$ of vintage $v .\left(P_{c c}{ }^{\prime}\right)$ explicitly shows the allocation of labor.

\footnotetext{
${ }^{9}$ Sala-i-Martin (1996), p. 102
} 


$$
\begin{aligned}
& \text { Maximize } \sum_{t=1}^{T} \beta^{t-1} \frac{1}{1-\gamma}\left(C_{t}^{1-\gamma}-1\right) \\
& \text { over } C_{t}, Y_{t v}, K_{t v}, N_{t v} \quad \text { for } t=1 \ldots T \quad \text { for } v=1 \ldots V+t-1 \\
& \text { subject to: } \\
& C_{t} \geq 0 \\
& Y_{t v} \geq 0 \\
& N_{t v} \geq 0 \\
& Y_{t v}=\min \left(d_{t v} K_{t v}, a_{t v} N_{t v}\right) \\
& \sum_{v=1}^{V+t-1} N_{t v} \leq N_{t} \\
& \sum_{i=1}^{V+t-1} Y_{t v}-C_{t} \geq 0 \\
& K_{1}=\bar{K} \\
& K_{t+1}=\left[\begin{array}{ccc}
1 & & \\
& \ddots & \\
& & 1 \\
0 & \cdots & 0
\end{array}\right] K_{t}+\left[\begin{array}{cc}
0 & 0 \\
\vdots & \vdots \\
0 & 0 \\
-1 & 1
\end{array}\right]\left[\begin{array}{l}
C_{t} \\
Y_{t}
\end{array}\right] \quad \text { for } t=1 \ldots T-1 \\
& \text { where } \quad K_{t}=\left[K_{t, 1}, K_{t, 2}, \ldots, K_{t, V+t-1}\right]^{\prime}
\end{aligned}
$$

$\left(P_{c c}\right)$ is an equivalent statement of the problem, but the number of variables has been

reduced and the production function constraint has been broken into two separate parts so that the constraint functions are differentiable. In this version, $N_{t v}$ is no longer a choice variable. In the labor constraint, $N_{t v}$ has been replaced by $\frac{Y_{t v}}{a_{t v}}$. This can be done since $\frac{Y_{t v}}{a_{t v}}=N_{t v}$ when the labor constraint is binding. All of the constraints are now affine so that $\left(P_{c c}\right)$, when converted to a minimization, will be a convex programming problem and therefore have a unique global solution. It is this formulation that is used to generate results. 


$$
\begin{aligned}
& \text { Maximize } \sum_{t=1}^{T} \beta^{t-1} \frac{1}{1-\gamma}\left(C_{t}^{1-\gamma}-1\right) \\
& \text { over } \quad C_{t}, Y_{t v}, K_{t v} \quad \text { for } t=1 \ldots T \quad \text { for } v=1 \ldots V+t-1 \\
& \text { subject to: } \\
& C_{t} \geq 0 \\
& Y_{t v} \geq 0 \\
& Y_{t v}-d_{t v} K_{t v} \leq 0 \\
& \sum_{v=1}^{V+t-1} \frac{Y_{t v}}{a_{t v}}-N_{t} \leq 0 \\
& -\sum_{v=1}^{V+t-1} Y_{t v}+C_{t} \leq 0 \\
& K_{1}=\bar{K} \\
& K_{t+1}=\left[\begin{array}{ccc}
1 & & \\
& \ddots & \\
& & 1 \\
0 & \cdots & 0
\end{array}\right] K_{t}+\left[\begin{array}{cc}
0 & 0 \\
\vdots & \vdots \\
0 & 0 \\
-1 & 1
\end{array}\right]\left[\begin{array}{l}
C_{t} \\
Y_{t}
\end{array}\right] \quad \text { for } t=1 \ldots T-1
\end{aligned}
$$

The technology and labor parameters have constant growth rates, with $a_{t v}=\bar{a}\left(1+g_{a e}\right)^{-N+v}\left(1+g_{a d}\right)^{t-1}, d_{t v}=$ constant, and $N_{t}=\bar{N}(1+n)^{t-1}$. The parameter values particular to the clay-clay model are:

$$
T=45 \quad \bar{a}=3 \quad d_{t i}=3 \quad \bar{K}=(5,5) \quad \bar{N}=20 .
$$

The initial levels and productivity of labor and capital were chosen such that the economy is labor constrained initially. By having technology affect only the $a$ parameter, technology is said to be "purely labor enhancing" or "Harrod neutral." While a unit of capital is always capable of producing the same amount of output, improvements in technology enable society to achieve that output per machine by applying less labor. 
When technology is only disembodied, $a_{t v}$ is increasing in $t$ and constant in $v$; whereas it is increasing in $v$ and constant in $t$ when technology is only embodied. The most important result stemming from fixed factor production models with vintage capital is that they exhibit economic obsolescence unlike their non-vintage and putty-putty counterparts. This obsolescence is a direct consequence of the scarcity of labor.

The vintage model, unlike the non-vintage model, is characterized by a cyclic steady-state, not a constant one (Figures 13 and 14). This is due to the obsolescence of vintages and the discrete-formulation used here. In continuous time clay-clay models, capital of a particular vintage is either completely used or not used. The depth of capital, the number of vintages used each period, which in continuous time models is not restricted to integer values, adjusts to make this so. This leads to the "replacement echoes," discussed in Benhabib and Rustichini (1991), and Boucekkine et. al. (1998), which eventually dissipate. With the depth of capital restricted to integer values in this paper, not all of the available capital of the oldest productive vintage will generally be used. It is this discrete nature of the vintages that perpetuates the echo effect. The length of the steady-state cycle is equal to the depth of capital, which is constant in the steadystate cycle. The arithmetic average growth rate during the cycle is equal to the steady state growth rate in the disembodied technology model:

$$
g_{Y}=\left(1+g_{\text {tech }}\right)(1+n)-1=4.54 \%
$$

The optimal depth of capital is 5 vintages when $\gamma=1,6$ vintages when $\gamma=2$ or 3 , and 7 vintages when $\gamma=5$. 
The steady state savings rate is the same $1.52 \%$ in the non-vintage model across values of $\gamma$. Since all capital in the non-vintage model is equivalent, investment is simply the level required to keep labor fully employed with zero obsolescence. Because the savings rate determines the depth of capital (or vice versa) in the vintage capital model, the savings rate follows the same pattern as the depth of capital. The average savings rate over the steady state cycle is $7.60 \%$ for $\gamma=1,6.47 \%$ for $\gamma=2$ and 3 , and $5.67 \%$ for $\gamma=5$

There is conditional $\sigma$-convergence in the clay-clay model for both embodied and disembodied technology. For the disembodied case, there is convergence for different economies regardless of the value of $\gamma$. This can be seen in part by examining the outputeffective labor ratio as defined for the clay-clay model (Figure 15). ${ }^{10}$ For the non-vintage model, the output-effective labor ratio equals one as soon as the economy is labor constrained. The per capita output of economies in this model converges very quickly. All capital is homogeneous so any two economies that are labor constrained at the same point in time will have the same per capita output.

The convergence of per capita output ( $\sigma$-convergence) is affected by the values of $\gamma$ in the vintage capital model. In this model, the key to convergence is the depth of capital. Economies with the same steady state depth of capital have the same steady state output-effective labor ratio. The output-effective labor ratio is not affected by the initial capital value (Figure 17). In fact, the output-effective labor ratio for this model can be

\footnotetext{
${ }^{10} \theta_{t}$ in equation (8) is now defined as $\theta_{t}=a_{t, V+t-1}$, the technology of the latest vintage available.
} 
viewed as a rating of the technology in the capital stock. If the amount of stock allows full employment, and it only utilizes the latest technology, then the ratio is equal to one as in the disembodied technology case. As the depth of capital increases, the average level of technology represented by the capital stock decreases, and this is reflected in the output-effective labor ratio.

Economies with the same depth of capital will have convergent per capita output. This is because economies with the same depth of capital will be effectively utilizing the same average level of technology, and hence, are able to use the same quantity of capital. The difference between the outputs per capita of two economies which converge may not be exactly zero if the cycles do not line up exactly, but the difference in the outputs cycles around zero. Figure 18 shows $\sigma$-convergence for two economies with the same value of $\gamma$ but differing initial capital values. Figure 16 shows $\sigma$-convergence for economies with differing values of $\gamma$ ( 2 and 3 ), and both the same and differing initial values. Like the non-vintage model, this convergence occurs much more quickly than in the empirical convergence literature. Per capita output converges quickly in part because of the rapid $\beta$-convergence. This corresponds to the non-optimization work of Ramanathan (1973). As can be seen in Figure 14, the clay-clay model with embodied technology achieves its steady state cycle in less than 10 time periods. The model with disembodied technology achieves its steady state as soon as the economy is labor constrained (Figure 13).

Convergence in the clay-clay model is obviously much faster than the convergence seen in the empirical literature. However, it is an undeniable fact that 
obsolescence occurs in the world. Obsolescence occurs because all capital must be used with some scarce resource. The non-existence of perpetual motion machines means that at the very least capital must use energy if not labor to function. When that scarce resource becomes more valuable elsewhere, the capital becomes obsolete. The fact that obsolescence occurs implies both that some technology must be embodied and that factor proportions are somewhat rigid.

\section{Putty-Clay Model}

The putty-clay model serves as a bridge between the putty-putty and the clay-clay models. Leif Johansen (1959) first introduced the putty-clay model. Phelps (1963) extended Johansen's work by allowing the lifetime of capital (before obsolescence) to be a dependent variable rather than a parameter. ${ }^{11}$ Mathews (1964) generalized Phelps framework to show that the depth of capital can be affected by the savings rate. Bliss (1968) derives, under a partial equilibrium framework, several theorems regarding balanced growth. However, none of the previous articles placed the putty-clay framework in a representative agent or central planner setting. The production function for the puttyclay model is derived from the putty-putty model of section 4 .

$$
Y_{t v}=A_{t v} N_{t v}^{1-\alpha} K_{t v}^{\alpha}
$$

This is the same production function for each vintage that the central planner faces in $\left(P_{p p}\right)$, but in the putty-clay model the planner must impose a fixed capital-labor ratio,

\footnotetext{
${ }^{11}$ Phelps coined the term "putty-clay."
} 
$r_{v}>0$, for each vintage $v$. Fixing the capital-labor ratio does not limit the amount of labor that can be applied to a particular vintage, nor the amount of capital of a particular vintage that can be used. The capital-labor ratio only implies that if labor and capital are applied outside of the ratio, then either some capital or some labor is being unproductive.

This is similar to the clay-clay model. The implied capital-labor ratio of $\left(P_{c c}\right)$ is $\frac{a_{t v}}{d_{t v}}$. By fixing $r_{v}$, output in the putty-clay model can be written as:

$$
Y_{t v}=\min \left(A_{t v} r_{v}^{\alpha} N_{t v}, \frac{A_{t v}}{r_{v}^{1-\alpha}} K_{t v}\right)
$$

The minimum value will be the expression involving $N_{t v}$ when labor is the constraining factor, $K_{t v}$ if capital is the constraining factor, and they will be equal if $N_{t v}$ and $K_{t v}$ are used in the proportion of $r_{v}$. Writing the production function as in (11) highlights the relationship between the clay-clay and putty-clay models. $a_{t v}$ and $d_{t v}$ of the production function in $\left(P_{c c}{ }^{\prime}\right)$ are equivalent to $A_{t v} r_{v}^{\alpha}$ and $\frac{A_{t v}}{r_{v}^{1-\alpha}}$, respectively in (11). Hence, the central planner in choosing $r_{v}$ can raise the productivity of labor or capital arbitrarily high, but only by reducing the productivity of the other resource. Another relationship to the clay-clay model can be seen if $r_{v}$ is chosen to be a constant. In that 
case, the putty-clay model is equivalent to a clay-clay model with "Hicks neutral" technology growing at the same rate as $A_{t v} \cdot{ }^{12}$

If $r_{i}$ grows at a constant rate, $g_{r}$, then $a_{t v}$ increases at the constant rate $\left(1+g_{\text {tech }}\right)\left(1+g_{r}\right)^{\alpha}-1$, while $d_{t v}$ will change at the rate $\frac{1+g_{\text {tech }}}{\left(1+g_{r}\right)^{1-\alpha}}-1$. Harrod neutral, or purely labor enhancing, growth occurs if $d_{t v}$ is constant. This occurs when $g_{r}=g_{r}^{*}=\left(1+g_{t e c h}\right)^{\frac{1}{1-\alpha}}-1$. If $g_{r}>g_{r}^{*}, d_{t v}$ will decrease at a constant rate. When $g_{r}=g_{r}^{*}$, $a_{t v}$ grows at the rate $\left(1+g_{t e c h}\right)^{\frac{1}{1-\alpha}}-1$. In this manner, the putty-clay model may be calibrated to coincide with the clay-clay model of section 5.

It also leads to the question of how to measure technological growth. In the clayclay model, the measure of technological growth is the growth rate of $a_{t v}$. However, in the putty-clay model, technology is only a part of $a_{t v}$. If empirically the growth rate of $a_{t v}$ is used as the measure of technological growth, when the world is in fact putty-clay, then the estimate of technological growth may be significantly upwardly biased.

$\left(P_{p c}\right)$ is the discrete time, finite horizon, optimization putty-clay model. In this model, $C_{t}$ is the chosen level of consumption in period $t . Y_{t v}$ is the chosen level of output in period $t$ using capital of vintage $v . K_{t v}$ is the amount of capital of vintage $v$ available at time $t$. The model could be written with labor as a choice variable, but it has

\footnotetext{
${ }^{12}$ Hicks-neutral technological growth is when labor and capital productivity, $a_{t v}$ and $d_{t v}$, grow at the same rate.
} 
been eliminated as in $\left(P_{c c}\right) . r_{v}$ is the chosen capital-labor ratio for each vintage $v . N_{t}$ is the given labor stock each period. $A_{t v}$ is the given level of the technology stock each period for each vintage. $V$ is the number of vintages available at time $t=1 . T$ is the given total number of time periods.

$$
\begin{aligned}
& \text { Maximize } \sum_{t=1}^{T} \beta^{t-1} \frac{1}{1-\gamma}\left(C_{t}^{1-\gamma}-1\right) \\
& \text { over } \quad C_{t}, Y_{t v}, K_{t v}, r_{v} \quad \text { for } t=1 \ldots T \quad \text { for } v=1 \ldots V+t-1 \\
& \text { subject to: } \\
& C_{t} \geq 0 \\
& Y_{t v} \geq 0 \\
& Y_{t v}-\frac{A_{t v}}{r_{v}^{1-\alpha}} K_{t v} \leq 0 \\
& \sum_{v=1}^{V+t-1} \frac{Y_{t v}}{A_{t v} r_{v}^{\alpha}}-N_{t} \leq 0 \\
& -\sum_{v=1}^{V+t-1} Y_{t v}+C_{t} \leq 0 \\
& K_{1}=\bar{K} \\
& K_{t+1}=\left[\begin{array}{ccc}
1 & & \\
& \ddots & \\
& & 1 \\
0 & \cdots & 0
\end{array}\right] K_{t}+\left[\begin{array}{cc}
0 & 0 \\
\vdots & \vdots \\
0 & 0 \\
-1 & 1
\end{array}\right]\left[\begin{array}{l}
C_{t} \\
Y_{t}
\end{array}\right] \quad \text { for } t=1 \ldots T-1
\end{aligned}
$$

Unlike the putty-putty and clay-clay models, the putty-clay model cannot be rewritten as a convex programming problem. Therefore, multiple solutions to the model are possible, and the solutions need not be global. Two types of solutions, differing in the optimal path of $r_{v}$, were found for the embodied technology case using the non-interior path-following algorithm. 
The first type of solution has $r_{v}$ constant from an early time period through the terminal period. Analysis of the results suggests that there may be a local maximum for every constant level of $r_{v}$ up to some threshold level (Berger 2001). For example, two solutions of this type had the following parameter values with $A_{t v}=\bar{A}\left(1+g_{e}\right)^{v-1}\left(1+g_{d}\right)^{t-1}$, and $N_{t}=\bar{N}(1+n)^{t-1}$ :

$$
\begin{array}{lllll}
T=45 & g_{d}=0 & g_{e}=0.03 & \bar{A}=3 & \gamma=2 \\
\beta=0.97 & V=2 & \bar{K}=(5,5) & \bar{N}=20 &
\end{array}
$$

The first solution obtained for these parameter values has the capital-labor ratio equal to 1.9 from the third vintage (the first not given) through the final vintage. The growth rate of consumption cycles similarly to the clay-clay model but not in a well-defined pattern. The growth rate from the twentieth to the thirty-fifth time period averaged $4.72 \%$. The depth of capital decreases during these periods from 6 to 4 vintages. A second solution of the same type has the capital-labor ratio equal to 1.0 from the third vintage onward. The solutions do not achieve a steady-state cycle within the specified time horizon.

The solutions with $r_{v}$ constant are equivalent to a clay-clay model with Hicks neutral growth and thus they will eventually go to a steady state where the depth of capital is 1 vintage, and the steady state growth rate is $g=\left(1+g_{e}\right)(1+n)-1$. Constructing series created with the same parameters as above but with $\bar{A}=1, r_{v}=1$ and constant savings rate of $5,10,15$, and $20 \%$, it takes $103,80,66$, and 56 time periods, respectively, for the depth of capital to achieve a steady state of 1 vintage. With $\bar{A}=3$, as in the 
numerical analysis of the clay-clay model, it takes $66,43,29$, and 19 periods respectively.

The second solution type discovered shows $r_{v}$ increasing over time. $r_{v}$ increased from the third period onward but not at a constant rate. This solution also did not reach a steady state.

In general, solutions to the putty-clay model are difficult to obtain. The programs require many iterations and often become mired at a point distant from a solution.

Obtaining results for problems with longer time horizons is impractical at this time. To shed more light on the models, series were generated using a constant savings rate and a constant growth rate of the capital-labor ratio. The following parameter values were used:

$$
\begin{array}{llll}
T=2000 & g_{d}=0 & g_{e}=0.03 & \bar{A}=1 \\
\beta=0.97 & V=2 & \bar{K}=(5,5) & \\
n=0.015 & \bar{N}=20 & \gamma=1,2,3,5 & \\
\bar{r}=1 & g_{r}=0.2 \%-10 \% & s=0.04-0.24
\end{array}
$$

A different series was created for each of the $g_{r}$ and $s . g_{r}$ was increased in increments of $0.2 \%$, and $s$ was increased in increments of 0.02 .550 series were created of 2000 periods each. Despite the fact that there is no optimization in the creation of series, the $\gamma$ parameters are included because the total discounted utility of consumption for each series was calculated (Figure 19). Table 1 gives the levels of $r$ and $s$ that achieved the greatest value of discounted utility for each of the $\gamma$ values. None of the previous papers that have examined putty-clay models have used utility functions. 
Only when the growth rate of $r$ was 0.046 and the savings rate was $0.06-0.24$ was the depth of capital sustained at a level other than $V+t-1$ (all) or 1 over the entire 2000 periods. This is not surprising since $g_{r}^{*}=0.0465$ for the chosen parameter values. The depth of capital is only sustainable at an intermediate value when technology is purely labor enhancing. This knife's edge result corresponds to the results of Solow et. al. (1966) and Bliss (1968). In fact, with $g_{r}=0.046$ the series didn't achieve a steady state after 2000 periods. Given enough time, the depth of capital would go to 1 . This shows how long the transition to the steady state can be in the vintage capital putty-clay model. The steady-state depth of capital for a 3000 period series and $g_{r}=g_{r}^{*}$ is summarized in Table 2.

Asymptotic growth rates of output were also calculated for each of the series. The growth rates for each $g_{r}$ were constant across $s$ and increased by a constant amount for each $0.2 \%$ increment in $g_{r}$, until $g_{r}^{*}$ (Table 3). When $g_{r}>g_{r}^{*}$ the growth rate of output goes to zero. The growth rate of output will not go to a steady state unless the depth of capital has gone to a constant or includes all available capital. Thus if the change in the capital-labor ratio over time can be measured as close to $g_{r}{ }_{r}$, then convergence to a steady state growth rate is unlikely since the initial structural parameters will probably not remain valid for the entire transition. It is worthwhile to point out that none of the utility maximizing levels of $g_{r}$ were as close to $g_{r}^{*}$ as allowed. Thus, even though $g_{r}{ }_{r}$ and its accompanying maximum growth rate may be perceived as a golden rule rate of 
change, the transition to the maximum growth rate is slow enough that the value of the asymptotic rate is somewhat irrelevant.

The above results show that there will not in general be convergence of per capita output in the putty-clay model. The first argument against convergence of output is that there are multiple solutions to the problem. This should not be confused with the concept of multiple equilibria discussed by Galor (1996) in relation to club convergence. Multiple equilibria are said to occur if given different initial values there are differing long run output paths. The multiple solutions of this model say that economies with identical initial values and structural parameters could converge to entirely different paths of output that satisfy the optimality conditions. Also, the optimization results combined with the results of the constructed series show that it is unlikely that the optimal growth rate of the capital-labor ratio will go to $g_{r}^{*}$. If two economies go to different constant rates of growth of the capital-labor ratio, then the economies will have differing long run growth rates and convergence is impossible.

\section{Conclusion}

Numerical results are obtained for the three basic utility maximizing growth models with vintage capital. Given the specified parameter values, the results for the putty-putty and clay-clay model are definitive in that they have unique global solutions. Numerical results have not been previously obtained for these vintage capital models, and in fact, vintage capital models with constant elasticity of intertemporal substitution utility functions have not been examined. Previous papers have only looked at asymptotic 
steady state results. The methods of this paper, however, allow the examination of the entire time path of the key economic variables. Therefore questions can be answered not only about $\beta$-convergence, but $\sigma$-convergence as well.

This examination reveals that although the steady states of vintage capital and non-vintage models may be characterized by similar growth rates, the transitions are quite different. While vintage and non-vintage putty-putty models demonstrate both $\beta$ convergence and $\sigma$-convergence, convergence rates are uniformly higher for the vintage models than for the non-vintage models. Furthermore, different preference parameters lead to different convergence rates for the vintage models (through changes in the savings rate), but not for the non-vintage model. Also, the optimization method reveals that for both vintage and non-vintage models, the value of $\gamma$ can affect whether the steady state growth rate is approached from above or below. Empirical evidence may therefore be difficult to interpret, since poor countries may grow faster or slower than rich countries if wealth is measured by per capita output and preferences vary across countries.

The differences between the vintage and non-vintage clay-clay models are more obvious than in the putty-putty model. The clay-clay model with vintage capital exhibits economic obsolescence of capital while the non-vintage model does not. The transition to the steady state takes somewhat longer in the vintage models and the steady-state, at least in discrete time models, is characterized by a cycle rather than a constant steadystate growth rate. The length of the cycle is equal to the depth of capital, and the arithmetic average of the growth rates during the cycle is equal to the non-vintage steadystate growth rate. Furthermore, since the value of $\gamma$ affects the optimal savings rate, and 
the savings rate determines the depth of capital, the depth of capital varies over the values of $\gamma$. Also, $\sigma$-convergence is seen across all values of $\gamma$ in the non-vintage case, but depends on $\gamma$ in the vintage case because $\gamma$ affects the depth of capital. Economies with the same depth of capital will conditionally converge in both the $\sigma$-convergence and $\beta$ convergence sense. For both the vintage and non-vintage clay-clay models with Harrodneutral technological growth, the transitions to the steady state growth rate and convergence of per capita output are faster than in the empirical literature.

While numerical results were obtained for the putty-clay model, they are not definitive. The putty-clay problem cannot be rewritten as a convex programming problem and has multiple solutions that are not all global solutions. One type of solution has a constant capital-labor ratio. Multiple solutions of this type were obtained. Another type of solution has an increasing capital-labor ratio. Neither type of solution achieves a steady-state growth rate before the terminal period specified. Hicks-neutral progress, which occurs with a constant capital-labor ratio, will lead to a steady state where eventually all or only one vintage of capital is used. The length of the transition will vary greatly depending on the savings rate and initial technology stock. Also, for a putty-clay model, an interior solution to the depth of capital exists only if the capital-labor ratio grows such that technological progress is purely labor-enhancing. This knife's edge result seems highly unlikely in the real world, as it fails to maximize utility when the savings rate and the growth rate of the capital-labor ratio are constrained to be constant from the initial period. If the growth rate in the capital-labor ratio is merely close to this knife's edge result, it can take thousands of years to complete the transition to the steady state, 
which is obviously much slower than the empirical literature suggests. If empirically it can be shown that different countries have different growth rates in their capital-labor ratios, then the putty-clay model concludes that the countries will converge in the long run to differing growth rates, despite the fact that their capital depths may all be going to one. Differing long run growth rates implies a lack of both $\sigma$-convergence and $\beta$ convergence. Conditional $\sigma$-convergence is also unlikely given that the multiple numerical solutions demonstrate that different output paths are possible for economies even if they have identical initial values and structural parameters.

The neoclassical models studied in this paper are simpler in terms of the origins of growth than the endogenous growth models that are in vogue today. However, even these neoclassical models show that under relatively simple assumptions about how technology enters the economy, and straightforward dynamics, the steady state may be many years in the future. Therefore, the study of the transition is important and the vintage capital models presented here illustrate that the transition is affected by the modeling of technology. Ignoring the fact that much of technology is embodied can lead to significant errors in the forecasting of convergence rates, expected depth of capital, and savings rates. 


\section{Appendix 1. Conditions for $\sigma$-convergence and $\beta$-convergence}

Per capita output at time $t$ for two economies, $y_{t}^{1}$ and $y_{t}^{2}$, can be viewed as sequences. $\sigma$-convergence, the convergence of per capita output, is said to occur if and only if:

$$
\lim _{t \rightarrow \infty}\left|y_{t}^{1}-y_{t}^{2}\right|=0
$$

The definition of $\beta$-convergence or "poor economies grow faster than rich economies" depends on how "poor" and "rich" are measured. If they are measured in terms of per capita output then $\beta$-convergence occurs if and only if:

$$
y_{t}^{i}>y_{t}^{j} \quad \forall t \quad \Leftrightarrow \quad \frac{y_{t+1}^{i}}{y_{t}^{i}}<\frac{y_{t+1}^{j}}{y_{t}^{j}} \quad \forall t
$$

If in the long run the growth rate of the two economies approach constant growth rates, $g^{i}$ and $g^{j}$, then it is obvious that in order for there two be $\beta$-convergence:

$$
g^{i}=g^{j}=g^{*}
$$

If (14) is not true when economies tend toward constant rates of growth, eventually the economy tending toward the higher growth rate will be richer, yet growing faster.

The assumption that economies converge to a common growth rate is not sufficient for $\beta$-convergence. A rich economy could converge to the growth rate from above, and the poor country from below. Sometimes in the literature it is assumed that rich countries only converge from below and the poor from above. This makes sense only when rich and poor are defined in terms of a steady state constant. Unfortunately, 
the fact that economies converge to a common growth rate is not sufficient to guarantee the existence of a steady-state constant.

The steady-state constant is derived by dividing output by something growing at the steady-state growth rate. Examining a single economy, let $\hat{y}_{t}=\frac{y_{t}}{(1+g)^{t}}$. Then for some finite constant $\mathrm{K}$ :

$$
\lim _{t \rightarrow \infty} g_{t}=g \quad \not \quad \quad \lim _{t \rightarrow \infty} \hat{y}_{t}=K
$$

To demonstrate $(15)$, the sequence $y_{t}$ can be written as a sequence which is a product of growth rates:

$$
y_{t}=y_{0}\left(1+g_{1}\right)\left(1+g_{2}\right) \ldots\left(1+g_{t}\right)
$$

where

$$
\lim _{t \rightarrow \infty} g_{t}=g
$$

So the limit of $\hat{y}_{t}$ can be rewritten:

$$
\lim _{t \rightarrow \infty} \hat{y}_{t}=\lim _{t \rightarrow \infty} \frac{y_{0}\left(1+g_{1}\right)\left(1+g_{2}\right) \ldots\left(1+g_{t}\right)}{\underbrace{(1+g)(1+g) \ldots(1+g)}_{t \text { times }}}
$$

Let $\alpha_{t}=\frac{1+g_{t}}{1+g}$. Then $\alpha_{t}>0$ and $\alpha_{t} \rightarrow 1$. It can be seen that the limit in (18) goes to a constant K, if and only if:

$$
\lim _{n \rightarrow \infty} \prod_{t=1}^{n} \alpha_{t}=\frac{K}{y_{0}}=K^{\prime}
$$

Let $\ln \left(\alpha_{t}\right)=\frac{1}{m_{t}}$. Then $\alpha_{t}=e^{\frac{1}{m_{t}}}$, and (19) becomes: 


$$
\lim _{n \rightarrow \infty} \prod_{t=1}^{n} \alpha_{t}=\lim _{n \rightarrow \infty} e^{\sum_{t=1}^{n} \frac{1}{m_{t}}}=K^{\prime}
$$

But (20) is only true if and only if:

$$
\lim _{n \rightarrow \infty} \sum_{t=1}^{n} \frac{1}{m_{t}}=\ln \left(K^{\prime}\right)
$$

In order for the $\sum_{t=1}^{n} \frac{1}{m_{t}}$ to converge to a constant as $n \rightarrow \infty, m_{t}$ must go to positive or negative infinity at faster than a linear rate (i.e. $\lim _{t \rightarrow \infty} \frac{m_{t+1}}{m_{t}}>1$ ). Thus, even if the growth rate of an economy goes to a constant, that alone does not guarantee the existence of a steady-state level such as the output-effective labor ratio.

However, suppose that the convergence rate of the growth rate of output is fast enough for the above to hold. Then suppose that for two economies:

$$
\lim _{t \rightarrow \infty} \hat{y}_{t}^{1}=\lim _{t \rightarrow \infty} \hat{y}_{t}^{2}=\hat{y}^{*}
$$

Restating (22):

$$
\lim _{t \rightarrow \infty}\left|\frac{y_{t}^{1}}{(1+g)^{t}}-\frac{y_{t}^{2}}{(1+g)^{t}}\right|=0
$$

If it is assumed that the sequences $\hat{y}_{t}^{1}$ and $\hat{y}_{t}^{2} \rightarrow \hat{y}^{*}$ monotonically, and that $\hat{y}_{t}^{1}-\hat{y}_{t}^{2}=\frac{y_{t}^{1}}{(1+g)^{t}}-\frac{y_{t}^{2}}{(1+g)^{t}} \rightarrow 0$ monotonically, then it can be shown that (13) holds, but the conditions do not guarantee $\sigma$-convergence. Rewriting (23):

$$
\lim _{t \rightarrow \infty}\left|\frac{1}{(1+g)^{t}}\left(y_{t}^{1}-y_{t}^{2}\right)\right|=0
$$


It is easy to see that (24) will remain true as long as the difference in per capita output grows at a rate less than $g$, which is not precluded by any of the above assumptions. Thus the statement "poor countries grow faster than rich countries" is not sufficient for convergence of per capita output, though it is obviously necessary. 


\section{TABLES}

Table 1.1. Putty-Clay Model: Growth rate of capital-labor ratio and savings rate achieving maximum utility for 2000 period series

\begin{tabular}{|c|c|c|c|c||}
\hline$\gamma=$ & 1 & 2 & 3 & 5 \\
\hline$r$ rate & 0.062 & 0.078 & 0.032 & 0.002 \\
\hline$s$ & 0.24 & 0.22 & 0.18 & 0.12 \\
\hline
\end{tabular}

Table 1.2. 3000 Period Series: $g_{r}=g_{r}^{*}$

\begin{tabular}{||l|c|c|c|c|c|c|c|c|c|c||}
\hline s & 0.24 & $\ldots$ & -0.02 & $\ldots$ & 0.14 & 0.12 & 0.10 & 0.08 & 0.06 & 0.04 \\
\hline depth & 5 & $\ldots$ & +1 & $\ldots$ & 10 & 13 & 17 & 25 & 3001 & 3001 \\
\hline $\begin{array}{l}\text { growth } \\
\text { rate }\end{array}$ & 0.0622 & $\ldots$ & $\ldots$ & $\ldots$ & $\ldots$ & $\ldots$ & $\ldots$ & 0.0622 & 0.0600 & 0.0400 \\
\hline
\end{tabular}

Table 1.3. Growth Rate of Output

\begin{tabular}{|l|c|c|c|c|c|c|c|c||}
\hline$g_{r}$ & 0 & $0.2 \%$ & $0.4 \%$ & $\ldots$ & $+0.2 \%$ & $\ldots$ & $4.4 \%$ & $g_{r}^{*}=4.65 \%$ \\
\hline growth rate & $4.55 \%$ & $4.62 \%$ & $4.69 \%$ & $\ldots$ & $+0.07 \%$ & $\ldots$ & $6.13 \%$ & $6.22 \%$ \\
\hline
\end{tabular}




\section{FIGURES}

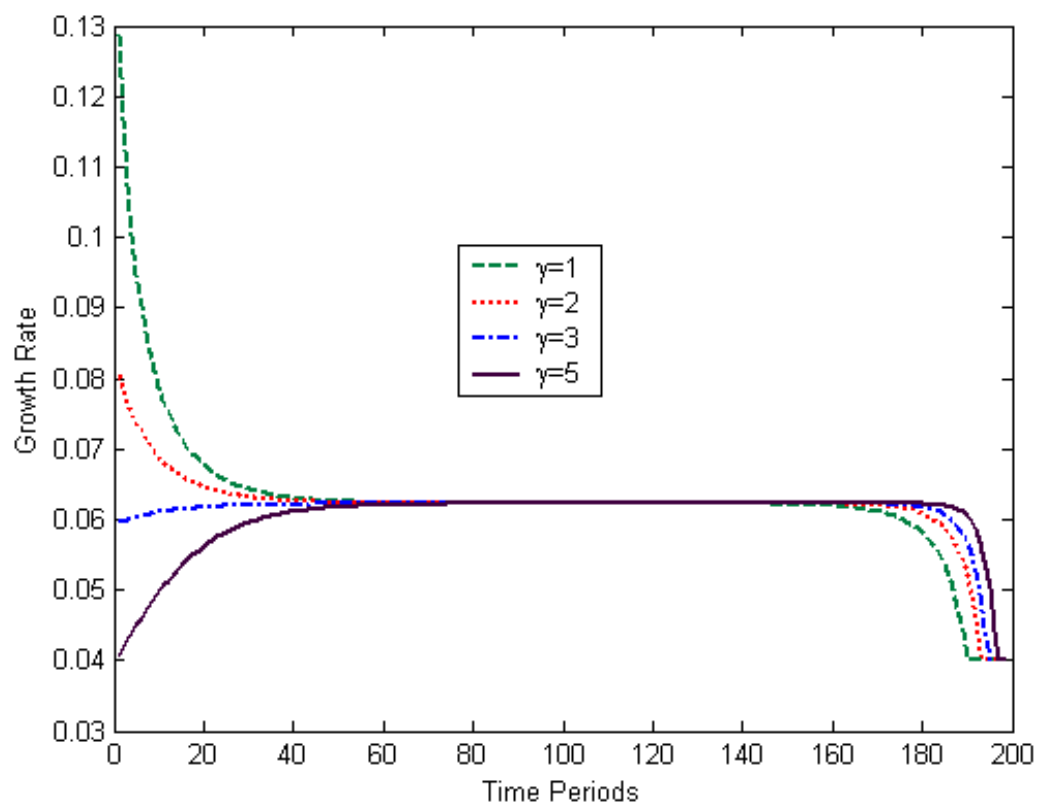

Figure 1. Growth Rate of Output, Putty-Putty, Disembodied Technology

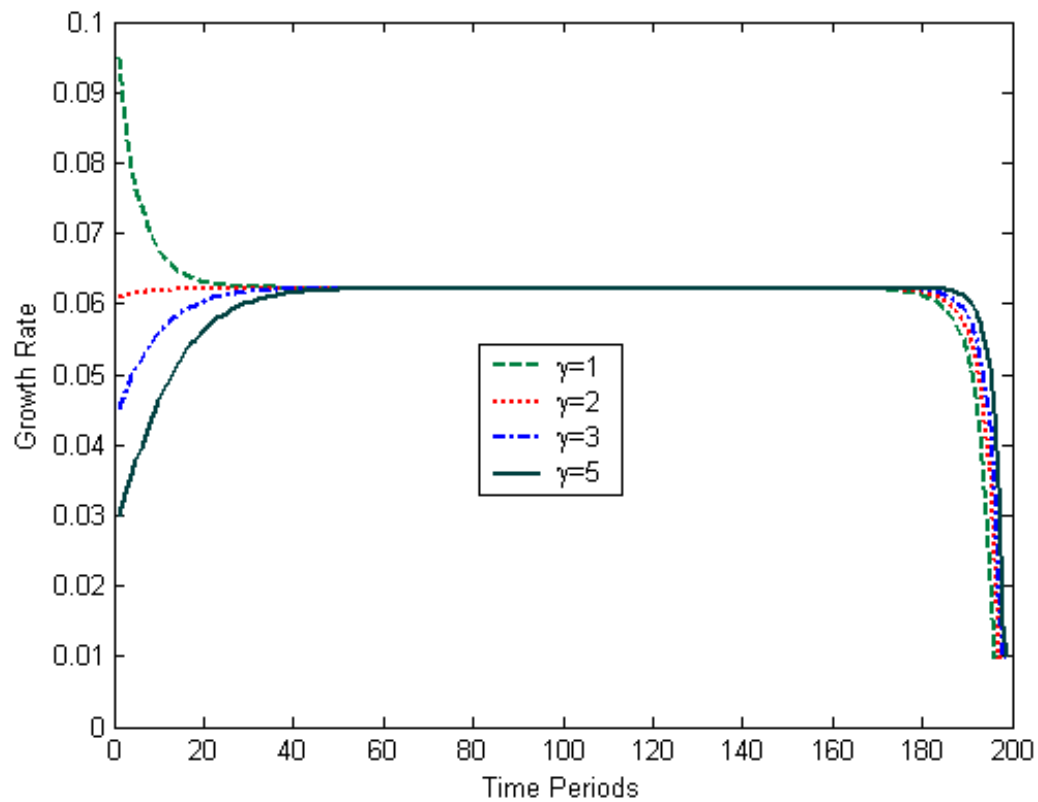

Figure 2. Growth Rate of Output, Putty-Putty, Embodied Technology 

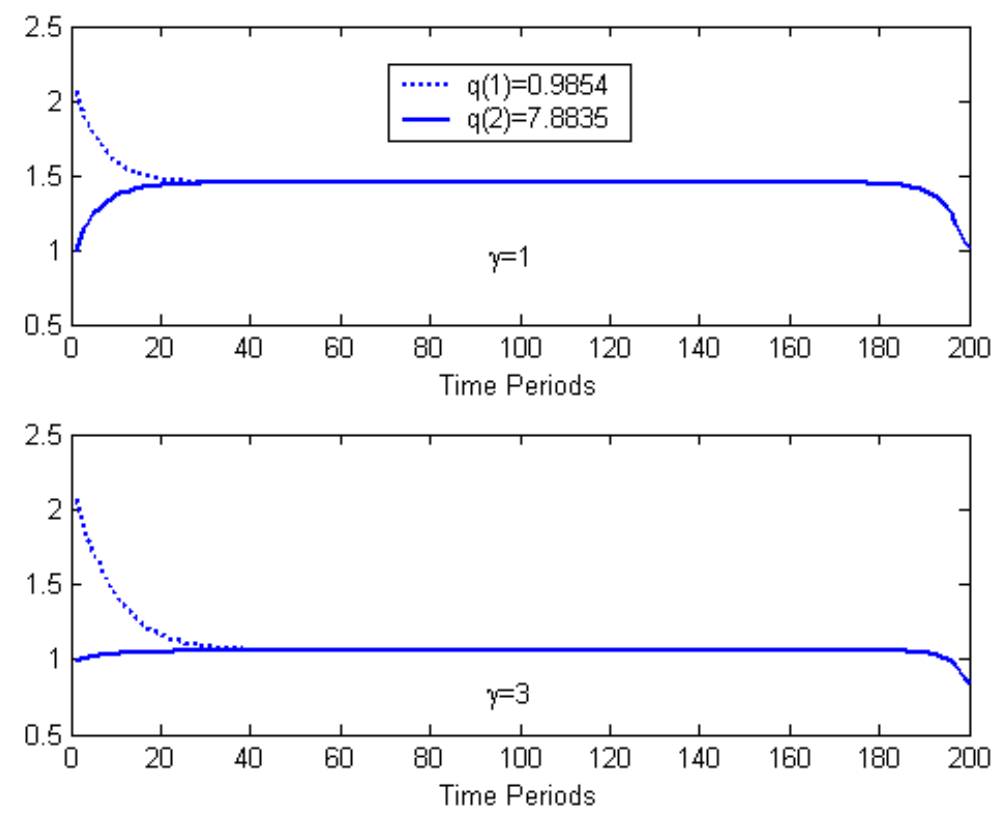

Figure 3. Output-Effective Labor Ratio, Putty-Putty, Embodied Technology, Rich vs. Poor
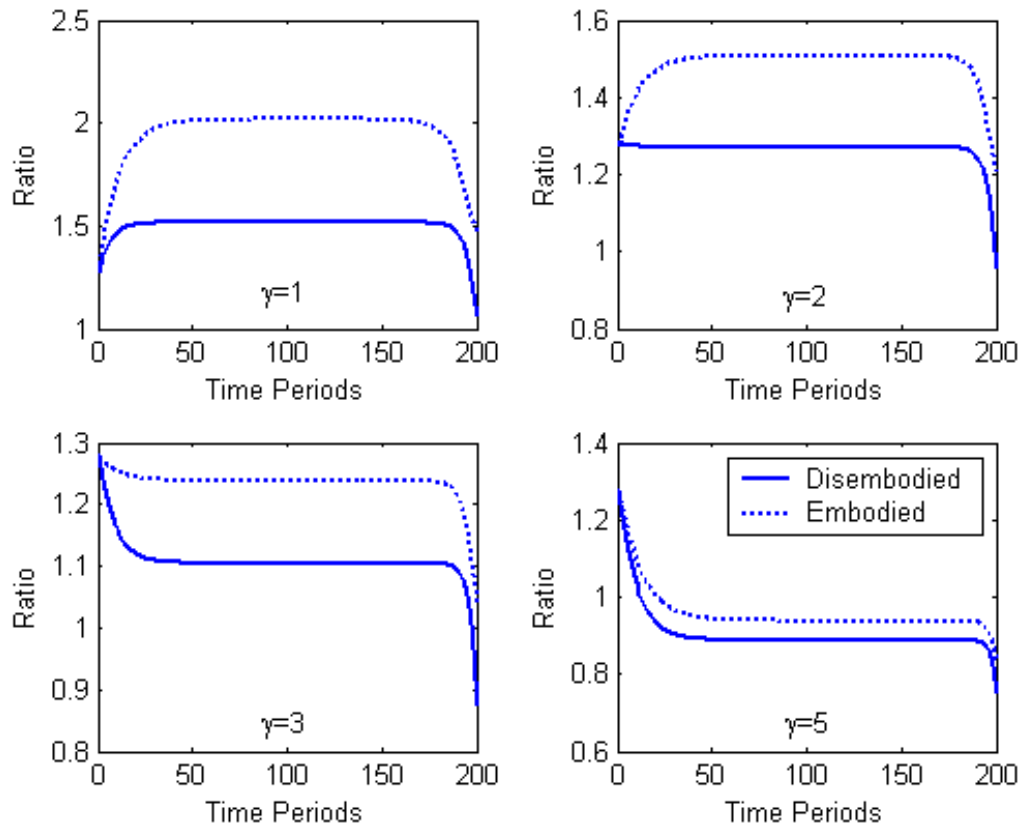

Figure 4. Output-Effective Labor Ratio, Putty-Putty 


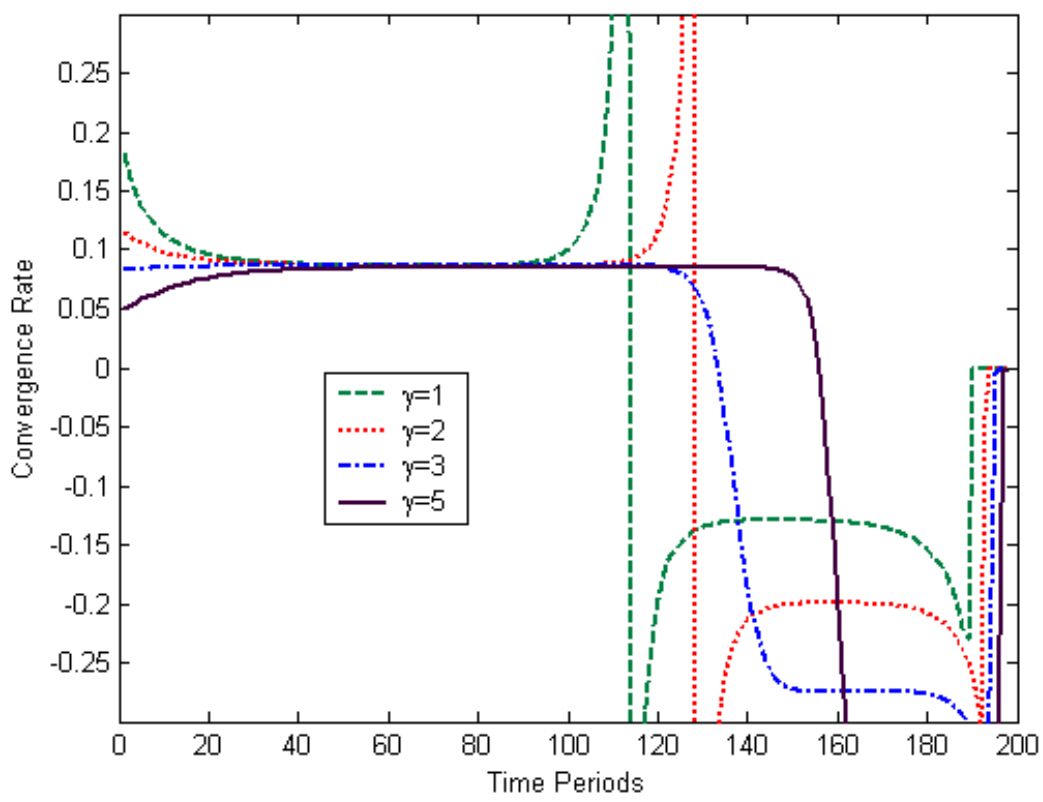

Figure 5. $\beta$-convergence Rate, Putty-Putty, Disembodied Technology

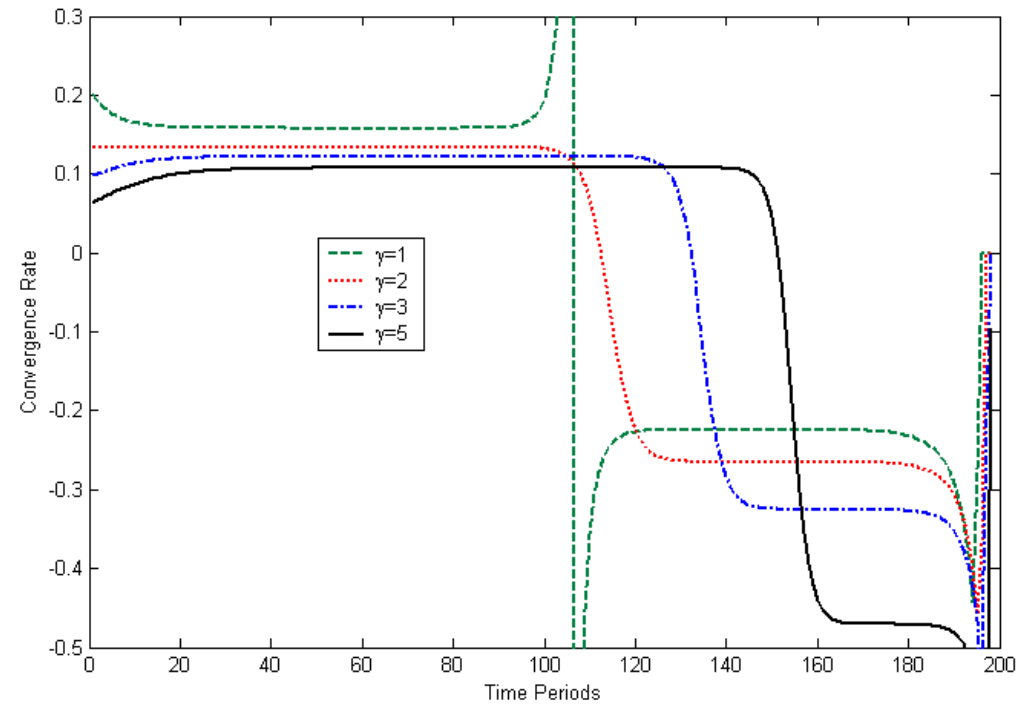

Figure 6. $\beta$-convergence Rate, Putty-Putty, Embodied Technology 

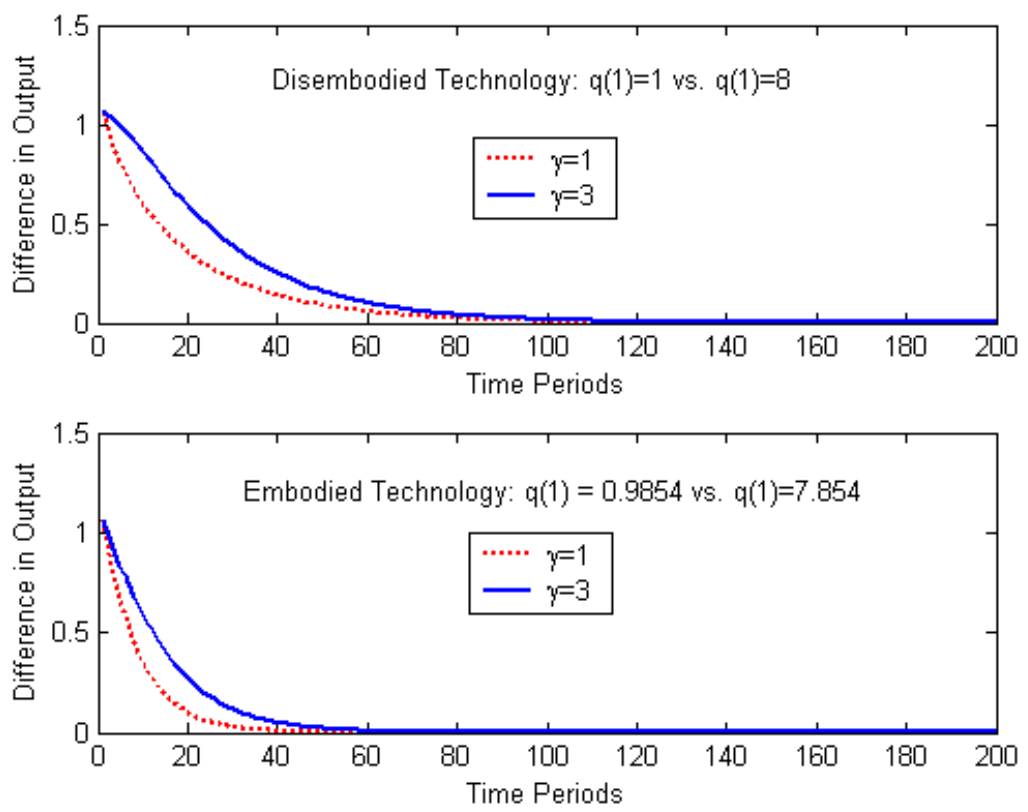

Figure 7. Convergence of Per Capita Output, Putty-Putty

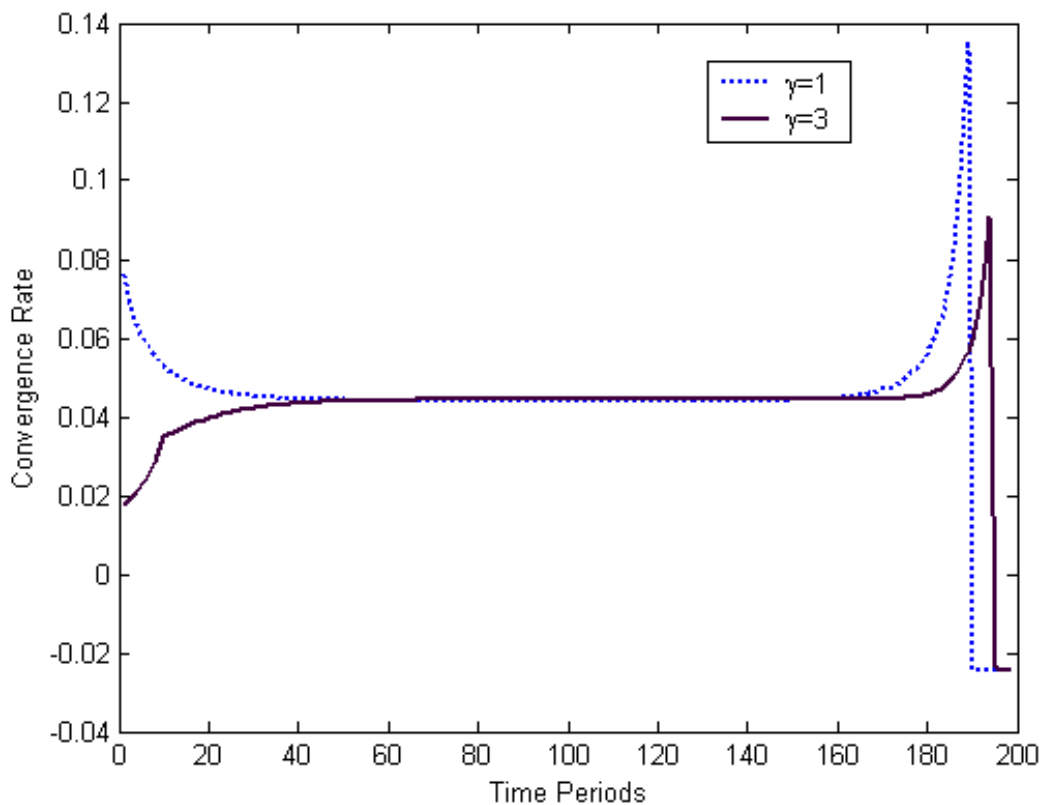

Figure 8. $\sigma$-convergence Rate, Putty-Putty, Disembodied Technology 


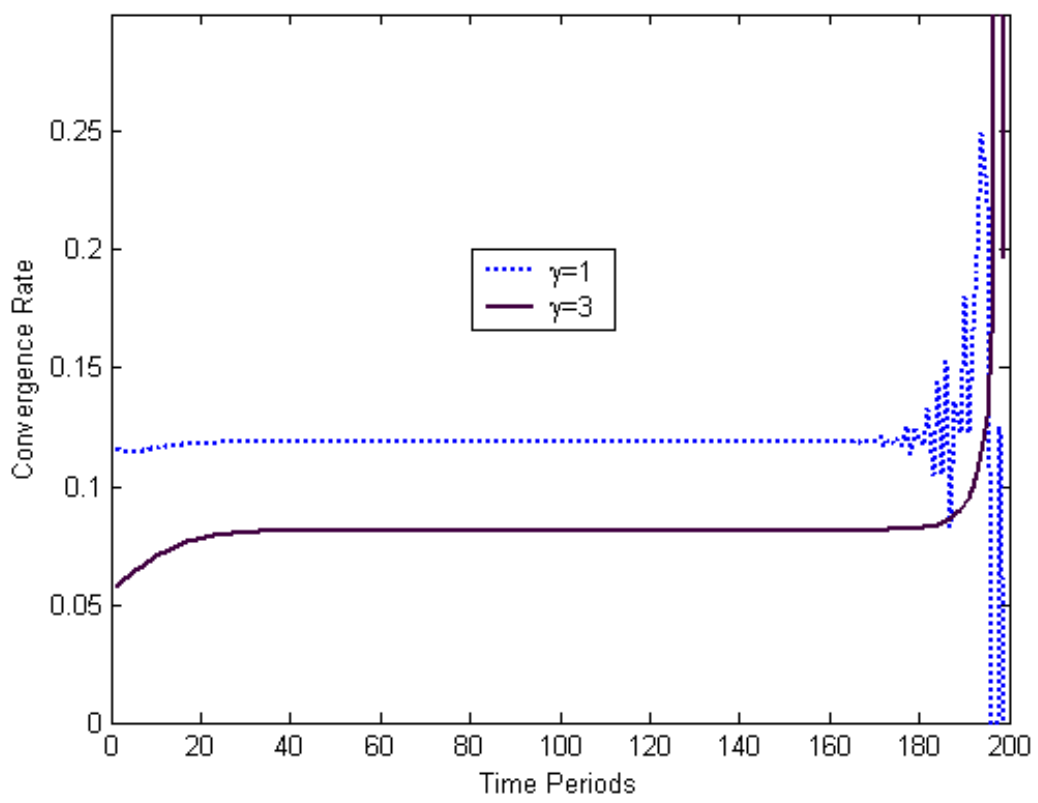

Figure 9. $\sigma$-convergence Rate, Putty-Putty, Embodied Technology

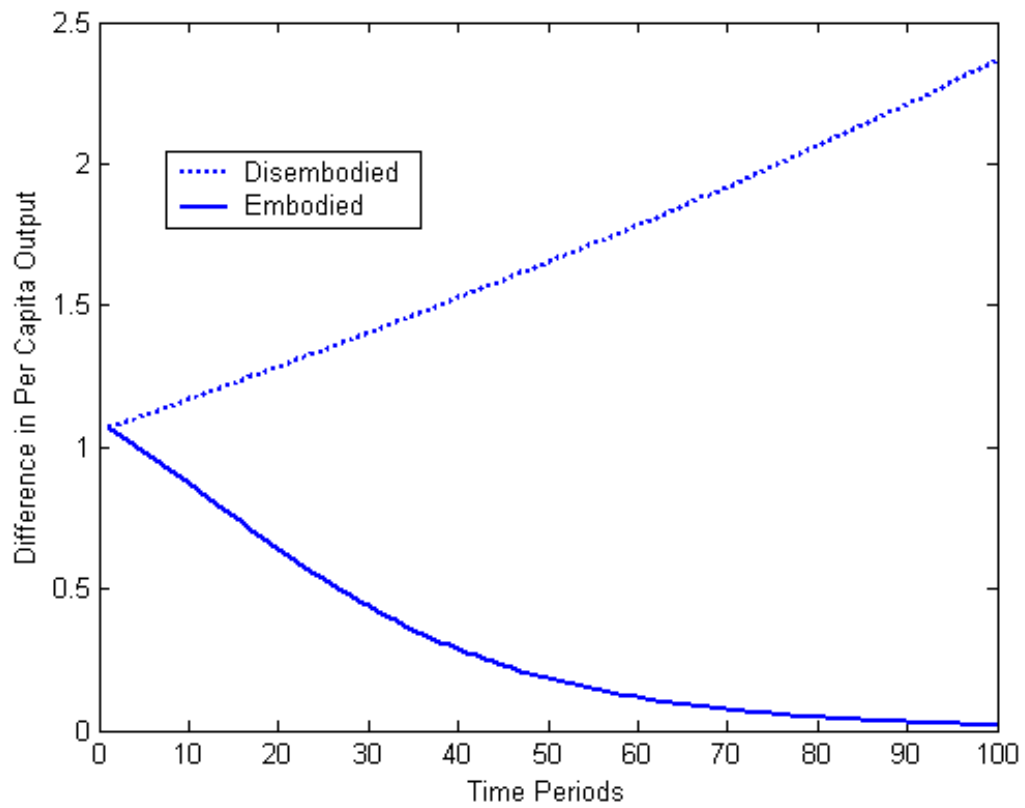

Figure 10. Convergence of Per Capita Output, Putty-Putty Series, savings rate $=0.1, \mathrm{q}_{1}=2$ vs. $\mathrm{q}_{1}=8$ 


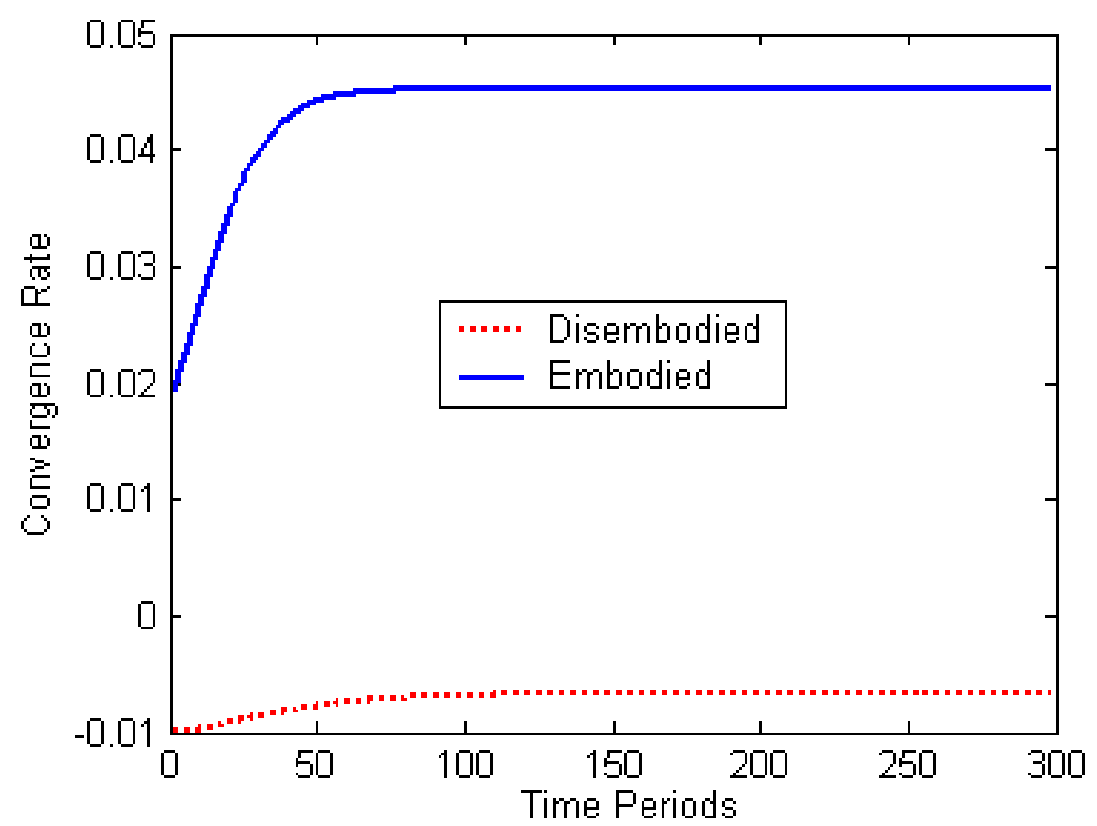

Figure 11. $\sigma$-convergence Rate, Putty-Putty Series, savings rate $=0.1, \mathrm{q}_{1}=2$ vs. $\mathrm{q}_{1}=8$

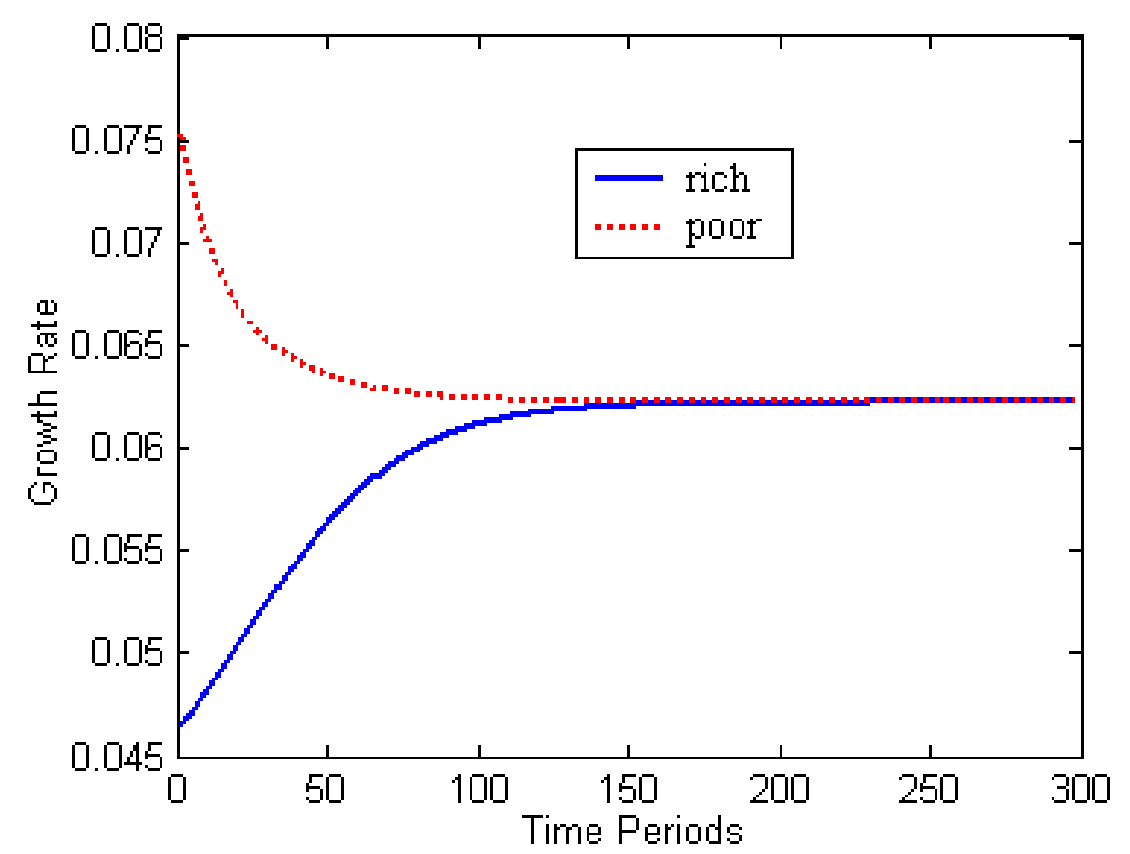

Figure 12. Growth Rates, Putty-Putty Series, savings rate $=0.1$, disembodied technology 


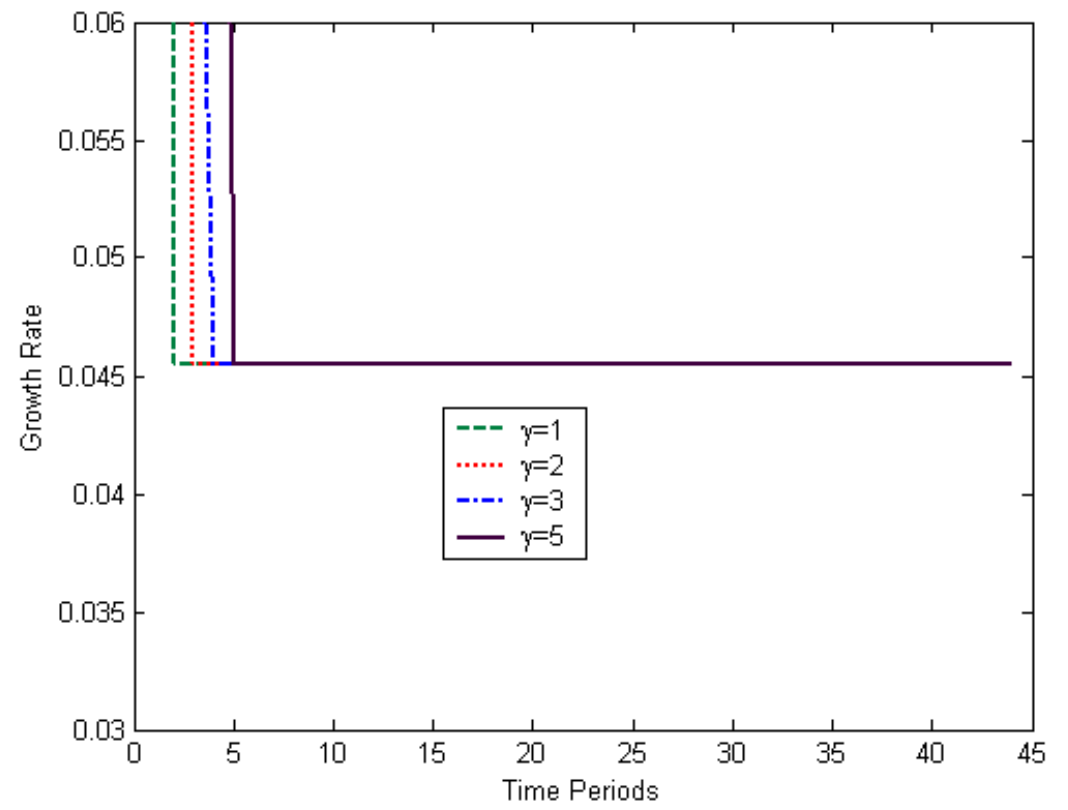

Figure 13. Growth Rate of Output, Clay-Clay, Disembodied Technology
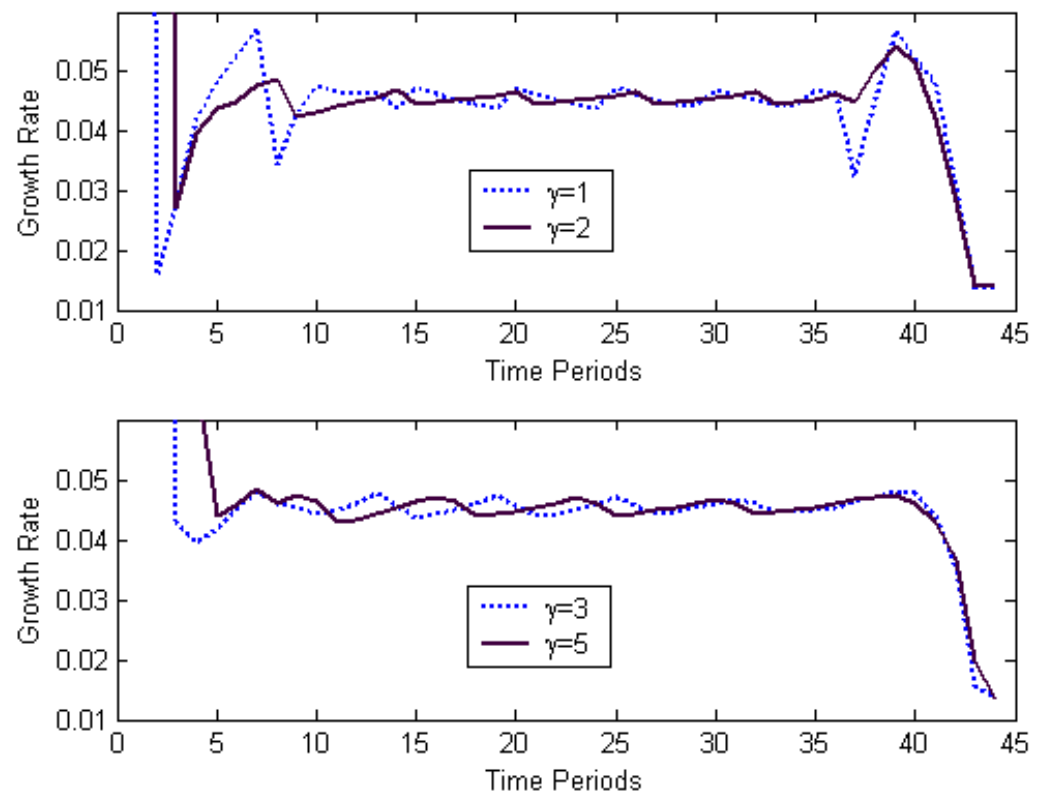

Figure 14. Growth Rate of Output, Clay-Clay, Embodied Technology 

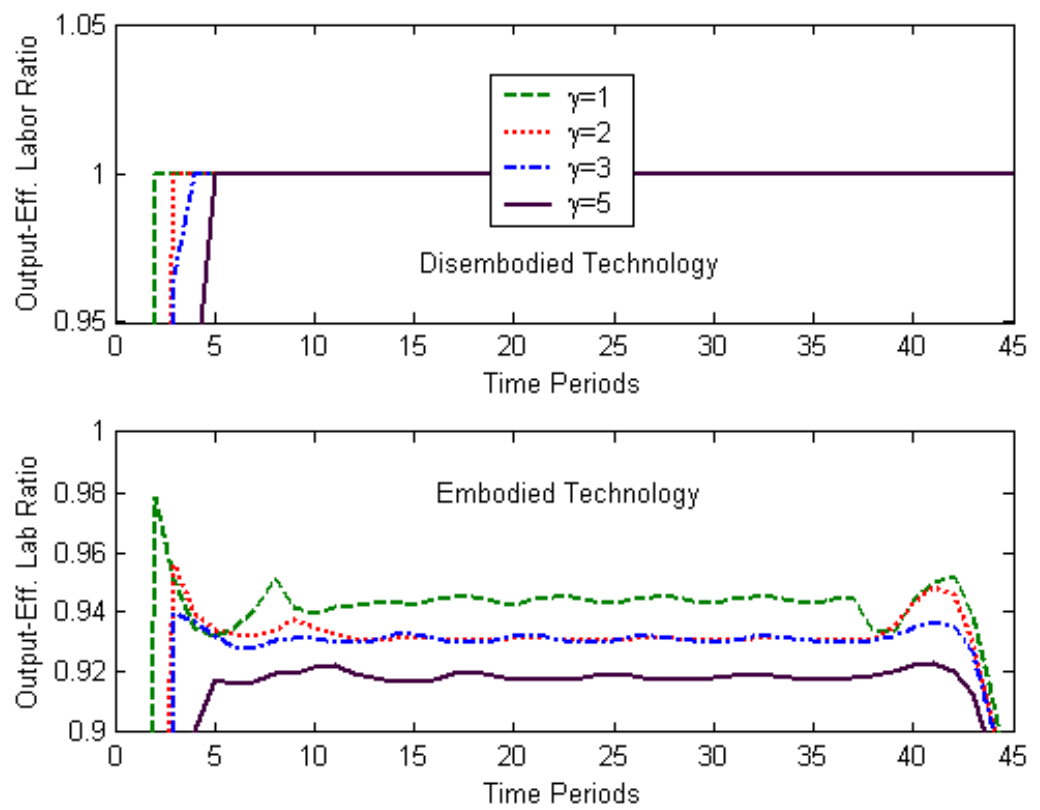

Figure 15. Output-Effective Labor Ratio, Clay-Clay

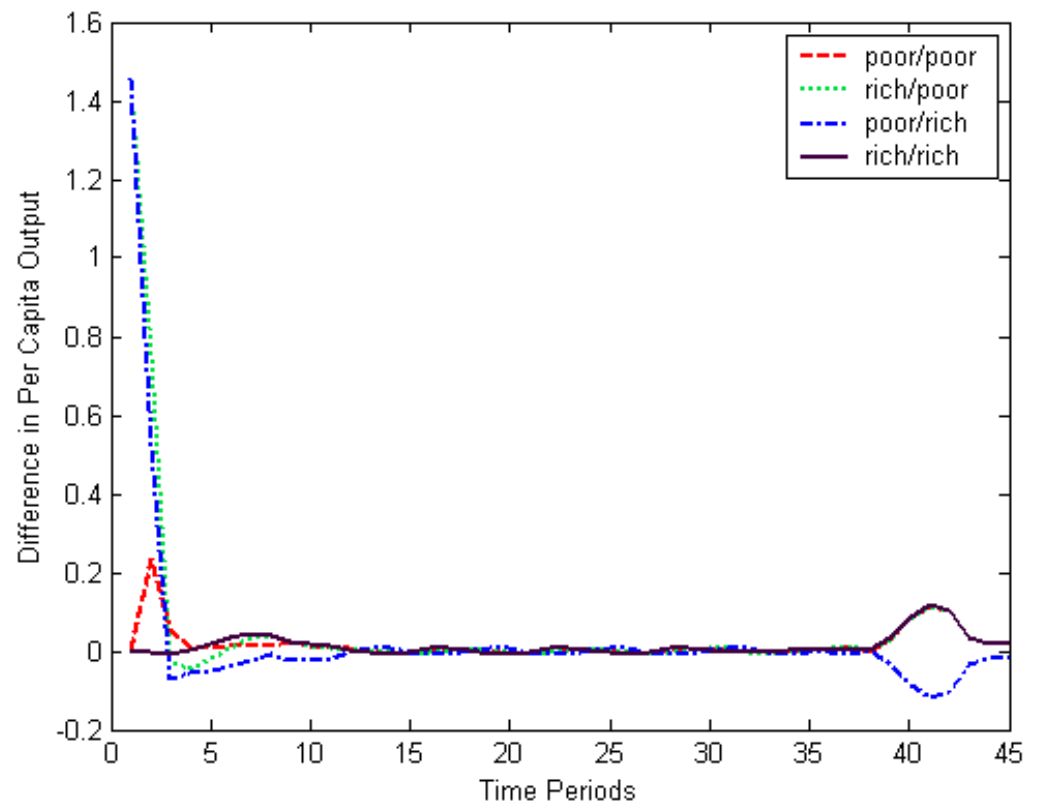

Figure 16. Convergence of Per Capita Output, Clay-Clay, Embodied Technology, $\gamma=2 / \gamma=3$ 

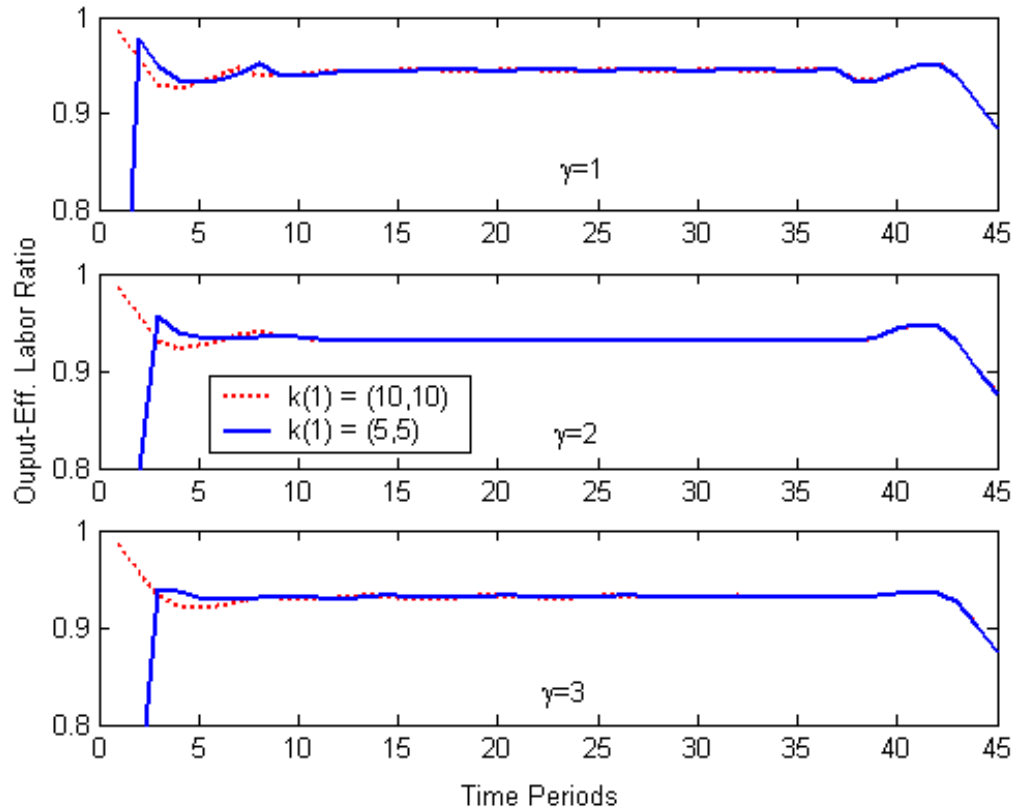

Figure 17. Output-Effective Labor Ratio, Clay-Clay, Embodied Technology, $\mathrm{k}_{1}=(5,5)$ vs. $\mathrm{k}_{1}=(10,10)$

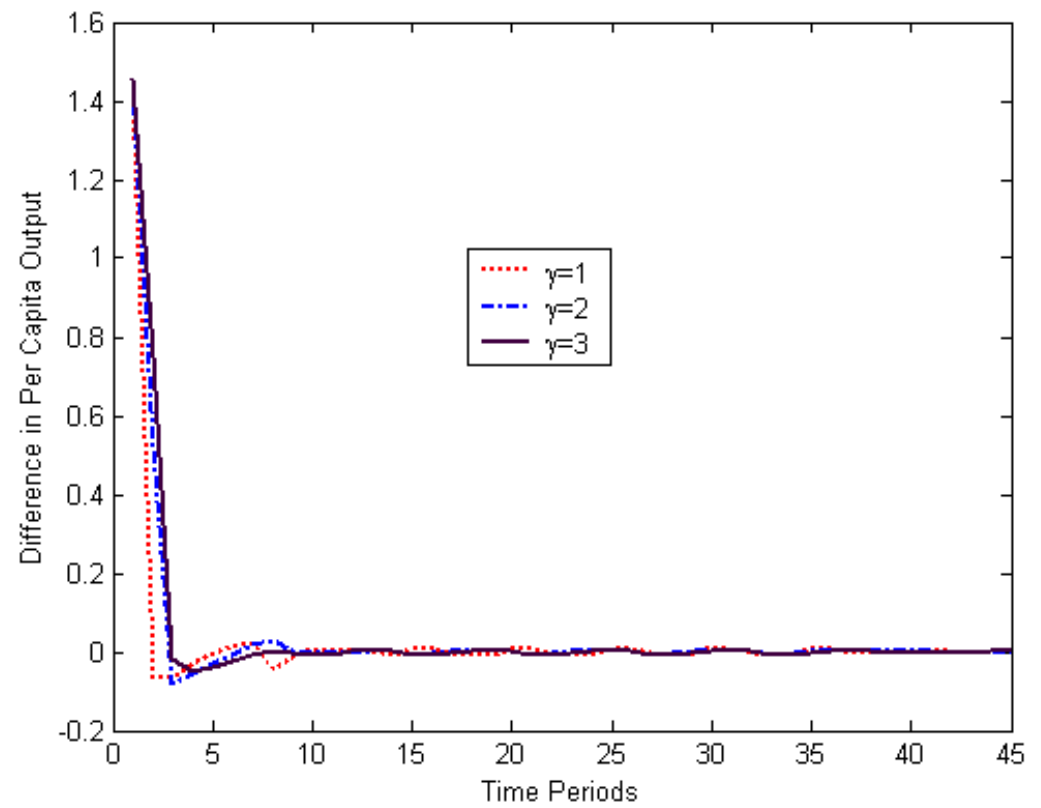

Figure 18. Convergence of Per Capita Output, Clay-Clay, Embodied Technology, $\mathrm{k}_{1}=(5,5)$ vs. $\mathrm{k}_{1}=(10,10)$ 

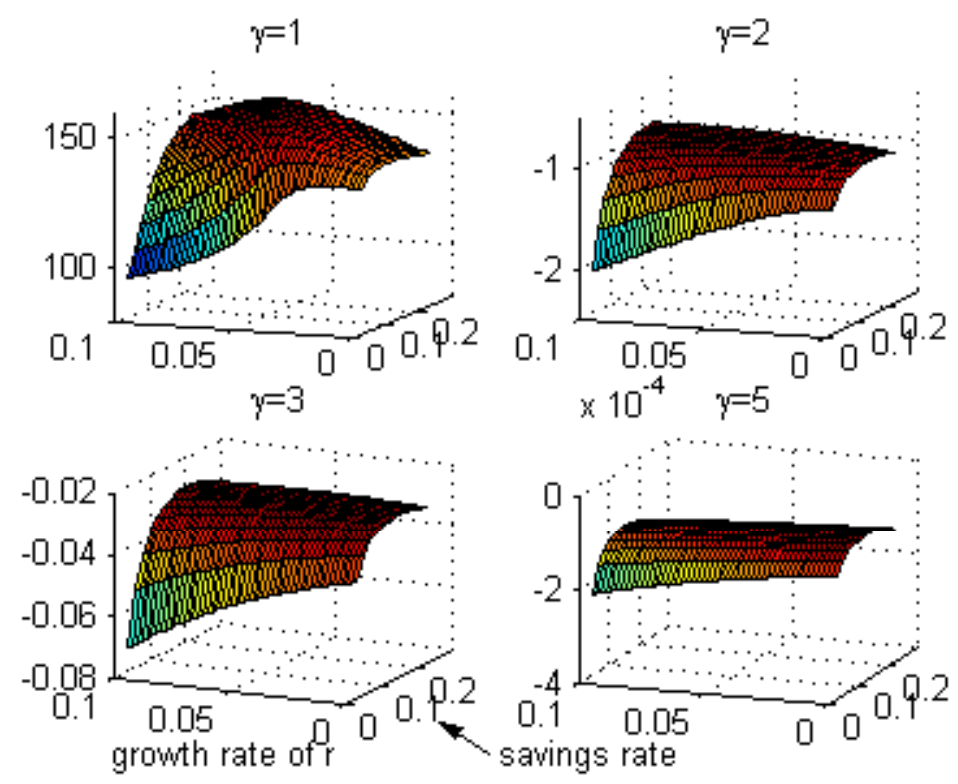

Figure 19. Discounted Utility, Putty-Clay Series: 2000 Periods,, Embodied Technology 


\section{References}

Barro, Robert J. (1991). "Economic Growth in a Cross Section of Countries.” Quarterly Journal of Economics 106, 407-443.

Barro, R., Sala-i-Martin, X. (1992). “Convergence.” The Journal of Political Economy $100,223-251$.

Barro, R., Sala-i-Martin, X. (1995). Economic Growth. McGraw Hill.

Benhabib, J., Rustichini, A. (1991). "Vintage Capital, Investment and Growth.” Journal of Economic Theory 55, 323-339.

Berger, Brett D. (2001). Dissertation, Paper 2. "Numerical Results for Neoclassical Growth Models Using Path-Following Algorithms."

Blanchard, O., Fischer, S. (1989). Lectures on Macroeconomics. MIT Press.

Bliss, C. (1968). “On Putty-Clay.” Review of Economic Studies, 35, 105-132.

Boucekkine, R., Germain, M., Licandro, O. and A. Magnus. (1998). "Creative Destruction, Investment Volatility, and the Average Age of Capital." Journal of Economic Growth 3, 361-384

Burke, J., Xu, S. (2000). “A Non-Interior Predictor-Corrector Path Following Algorithm for the Monotone Linear Complementarity Problem.” Mathematical Programming 87, 113-130.

Evans, P. (1997). “How Fast Do Economies Converge?" Review of Economics and Statistics 79, 219-225.

Galor, O. (1996). "Convergence? Inferences from Theoretical Model.” The Economic Journal 106, 1056-1069.

Greenwood, J., Z. Hercowitz, and P. Krussel. (1997). "Long-Run Implications of Investment-Specific Technological Change.” The American Economic Review 87, 342-362.

Johansen, L. (1959). "Substitution versus Fixed Production Coefficients in the Theory of Economic Growth: A Synthesis.” Econemetrica 27, 157-176. 
Maddison, A. (1987). "Growth and Slowdown in Advanced Capitalist Economies: Techniques of Quantitative Assessment.” Journal of Economic Literature 25, 649698.

Mankiw, N.G., Romer, D., Weil, D. (1992). "A Contribution to the Empirics of Economic Growth.” Quarterly Journal of Economics 107, 407-437.

Mathews, R. C. O. (1964). “The New View of Investment: Comment.” Quarterly Journal of Economics 78, 164-172.

Phelps, Edmund S. (1962). "The New View of Investment: A Neoclassical Analysis." Quarterly Journal of Economics 76, 548-567.

Phelps, Edmund S. (1963). "Substitution, Fixed Proportions, Growth and Distribution." International Economic Review 4, 265-288.

Quah, D. (1996). "Convergence Empirics Across Countries with (some) Capital Mobility." Journal of Economic Growth 1, 95-124.

Ramanathan, R. (1973). "Adjustment Time in the Two-Sector Growth Model with Fixed Coefficients." The Economic Journal 83, 1236-1244.

Sala-i-Martin, X. (1990). Ph.D. Dissertation, Harvard University.

Solow, Robert M. (1956). "A Contribution to the Theory of Economic Growth." Quarterly Journal of Economics 70, 65-94.

Solow, Robert M. (1959). "Investment and Technical Progress." Stanford Symposium on Mathematical Methods in the Social Sciences, 89-104.

Solow, R., J. Tobin, C. von Weizsäcker, and M. Yaari. (1966). "Neoclassical Growth with Fixed Factor Proportions." Review of Economic Studies 33, 79-155.

Wright, Stephen J. (1997). Primal-Dual Interior-Point Methods. Society for Industrial and Applied Mathematics. 